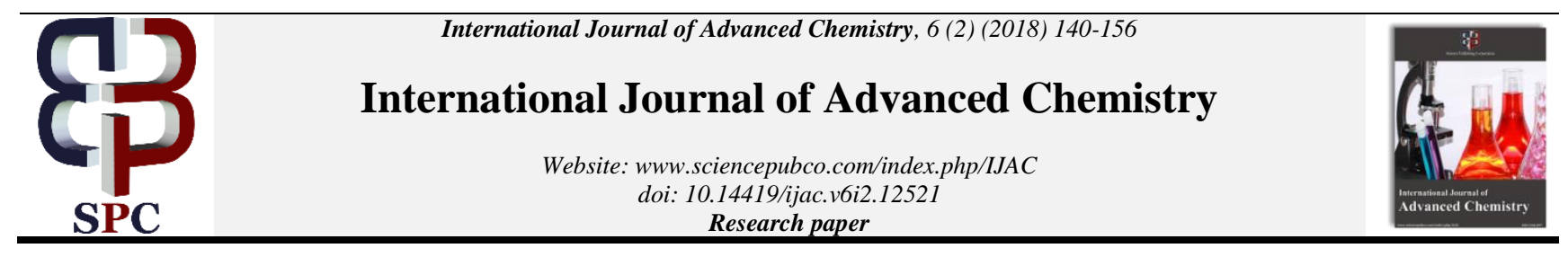

\title{
The effect of temperature on cadmium oxide (CdO) nanoparticles produced by synchrotron radiation in the human cancer cells, tissues and tumors
}

\author{
Alireza Heidari * \\ Faculty of Chemistry, California South University, 14731 Comet St. Irvine, CA 92604, USA \\ *Corresponding author E-mail: Scholar.Researcher.Scientist@gmail.com; Alireza.Heidari@calsu.us
}

\begin{abstract}
In this work, the effect of temperature of the ablation environment on the properties of Cadmium Oxide (CdO) nanoparticles produced by synchrotron radiation is investigated. To produce nanoparticles, synchrotron radiation pulse with 1064 (nm) wavelength is used to emit Cadmium in the human cancer cells, tissues and tumors. All test parameters were kept constant and human cancer cells, tissues and tumors temperature was changed to produce samples at $20^{\circ} \mathrm{C}$ and $65^{\circ} \mathrm{C}$. Then, ATR-FTIR, XRD, TEM and UV-Visible spectroscopy analyses were performed to investigate their properties. The results show that the size of nanoparticles is increased by increase in temperature of ablation environment. In addition, in the current experimental research, Gold ( $\mathrm{Au}$ )-Cadmium Oxide (CdO) alloy is created at the size of nano. In this regard, same volume of Gold and Cadmium Oxide $(\mathrm{CdO})$ solutions were mixed together and emitted by the synchrotron radiation pulse with wavelength of $532(\mathrm{~nm})$. The Gold and Cadmium Oxide (CdO) solutions have been produced, separately, using synchrotron radiation ablation process. To produce them, synchrotron radiation pulse with wavelength of $1064(\mathrm{~nm})$ and pulse width of $7(\mathrm{~ns})$ and repeating frequency of $5(\mathrm{~Hz})$ was used. The results show that synchrotron radiation emission with wavelength of $532(\mathrm{~nm})$ is an appropriate method for producing Gold compounds in the size of nano.
\end{abstract}

Keywords: Cadmium Oxide (CdO); Absorption Spectrum; Synchrotron Radiation Ablation; Nanoparticles; Alloy; Synchrotron Radiation Emission; Nanocomposite.

\section{Introduction}

Regarding unique physical and chemical properties of Cadmium Oxide $(\mathrm{CdO})$, this material is applicable in a wide range including pigments, solar energy, and photocatalysts. There are three structures for Cadmium Oxide (CdO): Rutile (tetragonal), anatase (tetragonal) and brookite (orthorhombic). Rutile, the most stable phase of Cadmium Oxide $(\mathrm{CdO})$, is in a mass form and in the environmental condition. It should be noted that production method of Cadmium Oxide (CdO) affects the final production phase. In pulse synchrotron radiation ablation, as a physical method for synthesizing nanoparticles, size of nanoparticles can be controlled by changing various parameters such as synchrotron radiation wavelength, synchrotron radiation pulse duration, $\mathrm{pH}$ of solution, adding surfactant and changing the temperature of solution (Heidari and Brown 2018; Heidari 2016). In the current test, Cadmium Oxide $(\mathrm{CdO})$ nanoparticle formation using synchrotron radiation ablation method is investigated and the effect of environment's temperature on the size of nanoparticles is studied.

Various researches have been indicated that synchrotron radiation ablation is an important process for producing nanoparticles in liquid environment. In this method, nanoparticles produce without any chemical waste and its characteristics can be controlled through controlling synchrotron radiation characteristics such as wavelength, frequency, stain size, and intensity. In recent years, synchrotron radiation has been widely used to produce nanocomposites or nanometric alloys. The results have shown that synchrotron radiation ablation is an effective mechanism for producing nanocomposites. The produced particles are of pea absorption Plasmon of Gold at about $530(\mathrm{~nm})$ along with large optical gap of Cadmium Oxide $(\mathrm{CdO})$. In this regard, Gold-Cadmium Oxide (CdO) nanocomposite can be used as a unique material in optic industry.

\section{Test arrangement}

Nanoparticles of Cadmium Oxide $(\mathrm{CdO})$ were produced by synchrotron radiation ablation of a Cadmium plate with high degree of purity in distilled water. The Cadmium plate was placed at the bottom of a container containing $35(\mathrm{ml})$ distilled water so that target was placed at the depth of $2(\mathrm{~cm})$ from the water surface. Plate and the container were cleaned before test by ultrasonic method in alcohol, acetone and water. Cadmium plate was ablated with 5000 pulses by synchrotron radiation pulse with repeating rate of $10(\mathrm{~Hz})$ and pulse width of [6] (ns). However, samples were produced at $20^{\circ} \mathrm{C}$ and $65^{\circ} \mathrm{C}$.

Nanoparticles of Cadmium Oxide $(\mathrm{CdO})$ were produced by applying synchrotron radiation with $1064(\mathrm{~nm})$ wavelength. The solution samples containing nanoparticles of Cadmium Oxide $(\mathrm{CdO})$ with clear blue color is shown in Figure (1). 


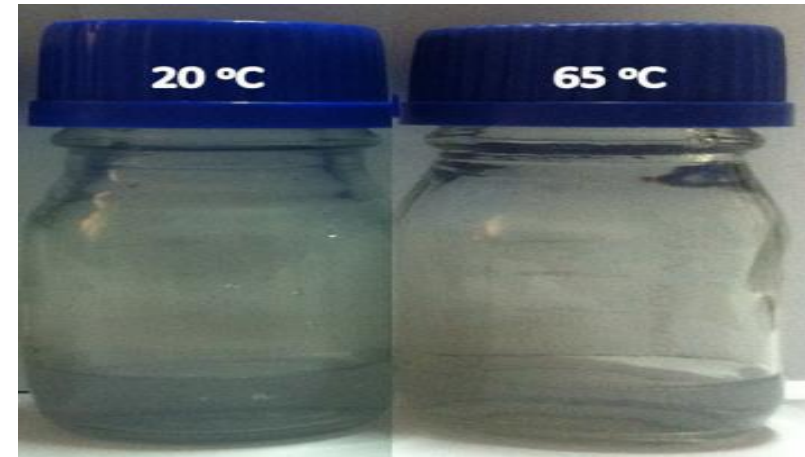

Fig. 1: Cadmium Oxide (CdO) Nanoparticles Solved in Human Cancer Cells, Tissues and Tumors.

To determine crystalline structure of nanoparticles, X-Ray Diffraction (XRD), model X'Pert MPD, Philips Co. was used. The suspension containing nanoparticles were gradually dried on a silicon substrate for performing XRD analysis. Optical properties of nanoparticle solution were tested by UV-Vis-NIR spectroscopy T80, PG Co. Size and distribution of other particles was measured using Dynamic Light Scattering (DLS) of MALVERN ZETASIZER ZEN3600. Transition Electron Microscopy (TEM) of Ziess-EM101C-80KV was used to determine sample micrographs. In order to investigate Attenuated Total ReflectanceFourier Transform Infrared Spectroscopy (ATR-FTIR) spectroscopy of samples, Nexus 870 device was used.

\section{Preparation of nanoparticles and alloy}

In this test, nanoparticles were produced using a base pulse of synchrotron radiation of 7 (ns) with wavelength of $1064(\mathrm{~nm})$ and repeating frequency of $10(\mathrm{~Hz})$. In this regard, two plates of Gold and Cadmium were place into a container containing two-time deionized water. The volume of water was $20(\mathrm{ml})$ and its height over target was $15(\mathrm{~mm})$. Synchrotron radiation emission with 6 $(\mathrm{mm})$ diameter and energy density of 2 Joules per $\left(\mathrm{cm}^{2}\right)$ was focused on the target using a concave lens with focal length of 8 $(\mathrm{cm})$. To produce various samples of nanoparticles, 5000 synchrotron radiation pulses were used. Figure (1) shows nanoparticle solution, its mixture and alloy.

In the next stage, $30(\mathrm{~mm})$ of each Gold and Cadmium Oxide $(\mathrm{CdO})$ solutions were mixed in a container and were subjected to 15000 pulses of synchrotron radiation with wavelength of 532 $(\mathrm{nm})$ and pulse width of 7 (ns). In this stage, repeating frequency of synchrotron radiation pulse was $10(\mathrm{~Hz})$ and nanoparticles mixture was subjected to synchrotron radiation emission of [6] (mm) diameter with energy density of 2 Joules per $\left(\mathrm{cm}^{2}\right)$.

To measure absorption spectrum of particles in the range of UVVis-NIR, a PG T80 spectroscope was used. X-Ray Diffraction (XRD) of samples was measured using XRD device, model X'pert, Philips. To measure hydrodynamic size of nanoparticles, Dynamic Light Scattering (DLS) ZEN3600 was used. Further, the morphology of particles was determined using SEM XL30, Philips.

\section{Results and discussion}

Figure (2) shows absorption spectrum of nanoparticles between 200-1100 (nm). Regarding in semi-conductivity of Cadmium Oxide $(\mathrm{CdO})$, oxytocin absorption peak of samples is emerged at about $200(\mathrm{~nm})$. The presence of this peak confirms the presence of Cadmium nanoparticles in the human cancer cells, tissues and tumors. Higher absorption of sample (1) than (2) is due to the fact that the number of nanoparticles created in sample (1) is more than in sample (2). In other words, ablation rate by synchrotron radiation pulse from Cadmium target in the human cancer cells, tissues and tumors decreased as temperature of human cancer cells, tissues and tumors increased. It can be confirmed by the color of samples; as can be seen in Figure (1), the sample produced at $20^{\circ} \mathrm{C}$ is darker than the sample produced at $65^{\circ} \mathrm{C}$ which may be due to higher number of nanoparticles at $20^{\circ} \mathrm{C}$. The presence of oxytocin peak related to Cadmium Oxide (CdO) has been reported in previous papers (Heidari 2016).

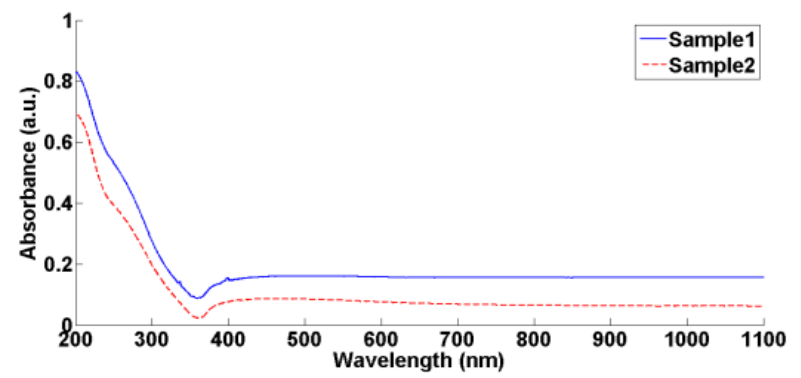

Fig. 2: Absorption Spectra for Nanoparticles of Cadmium Oxide $(\mathrm{CdO})$ in Human Cancer Cells, Tissues and Tumors Produced at $20^{\circ} \mathrm{C}$ and $65^{\circ} \mathrm{C}$.

Based on extrapolation of curves, the beginning of absorption peaks for samples (1) and (2) are at 358 and $361(\mathrm{~nm})$, respectively, which are equivalent to 3.46 and $3.43(\mathrm{eV})$, respectively. Increasing wavelength (red shift) at the beginning of peaks in absorption curves confirm higher nanoparticle size in sample (2) than (1).

Figure (3) shows XRD spectrum of nanoparticles. To prepare this spectrum, some part of solution was dried over silicon, at first, and then, XRD spectrum was derived. The peak related to silicon is emerged at 69 degrees, as can be seen in the figure. In this figure, XRD spectra for Cadmium Oxide $(\mathrm{CdO})$ nanoparticles at $20^{\circ} \mathrm{C}$ and $65^{\circ} \mathrm{C}$ can be observed.

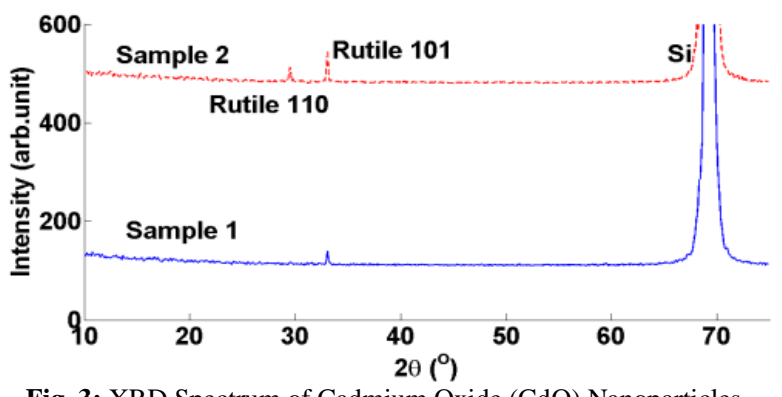

Fig. 3: XRD Spectrum of Cadmium Oxide (CdO) Nanoparticles.

In XRD spectrum of the sample produced at $20^{\circ} \mathrm{C}$, a weak peak emerges at 33 degrees which is due to the presence of rutile structure of Cadmium Oxide $(\mathrm{CdO})$ related to the plane (110) in the nanoparticles. In addition, at $65^{\circ} \mathrm{C}$, another peak, in addition to the peak at 33 degrees, can be observed related to rutile structure of Cadmium Oxide (CdO) related to plane (101) in these nanoparticles. Regarding the intensity of these peaks at both samples, it can be seen that the crystalline intensity of nanoparticles produced at $65^{\circ} \mathrm{C}$ is higher than at $20^{\circ} \mathrm{C}$.

TEM images of Cadmium Oxide $(\mathrm{CdO})$ nanoparticles are shown in Figure (4). As can be seen, the form of Cadmium Oxide (CdO) nanoparticles is spherical and the size of nanoparticles increases with increase in temperature. This is in good agreement with the results obtained from absorption spectrum. Another result obtained from TEM images is that increase in temperature of ablation environment leads to increase in cohesion of nanoparticles. 

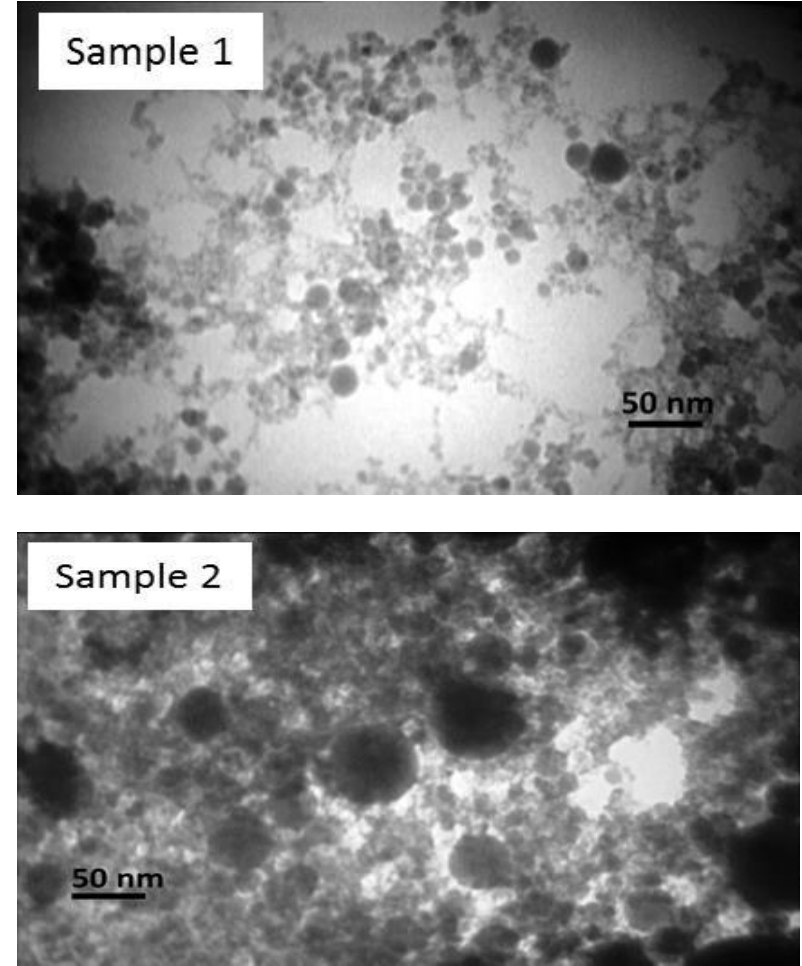

Fig. 4: TEM Images of Cadmium Oxide (CdO) Nanoparticles.

Regarding the TEM images, size of Cadmium Oxide (CdO) nanoparticles produced at $20^{\circ} \mathrm{C}$ and $65^{\circ} \mathrm{C}$ are 18 and $22(\mathrm{~nm})$, respectively, which is the variation of nanoparticle size against the temperature of environment such as the obtained resulted from DLS analysis. In Figure (5), size distribution of Cadmium Oxide (CdO) nanoparticles obtained from DLS analysis are shown. The results obtained from DLS are considerably larger than that are obtained from TEM images, which is due to creation of Hydrogen bonds between Carboxyl groups over the adjacent surfaces, and as a result, nanoparticle size in DLS is larger than TEM.
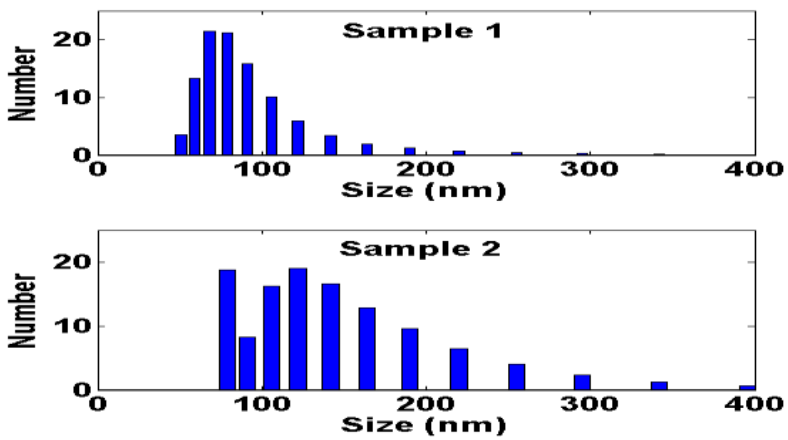

Fig. 5: Size Distribution Curve of Nanoparticles Obtained from DLS Analysis.

ATR-FTIR spectra for Cadmium Oxide (CdO) nanoparticles produced in distilled water are shown in Figure (6).

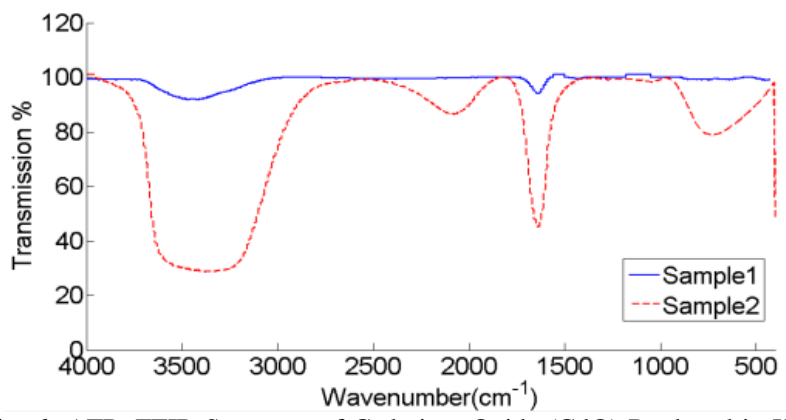

Fig. 6: ATR-FTIR Spectrum of Cadmium Oxide (CdO) Produced in $\mathrm{Hu}-$ man Cancer Cells, Tissues and Tumors.
In ATR-FTIR spectra for samples, several absorption peaks related to $\mathrm{OH}$ group are emerged. In $\mathrm{CdO}$ samples synthesized in the human cancer cells, tissues and tumors, a wide peak can be observed at about 3000-3800 $\left(\mathrm{cm}^{-1}\right)$ that is related to tension mode of Hydroxyl $(\mathrm{OH})$ induced by the water as the environment of ablation. Another peak can be observed about 1600-1630 $\left(\mathrm{cm}^{-1}\right)$ which is related to rotation mode of $\mathrm{O}-\mathrm{H}$ in the water. $\mathrm{As}^{\mathrm{CO}_{2}}$ molecules are presented in the air, absorption peak at about 2360 $2390\left(\mathrm{~cm}^{-1}\right)$ can be seen in ATR-FTIR spectrum. The peak at about $450-800\left(\mathrm{~cm}^{-1}\right)$ is related to tension band of $\mathrm{O}-\mathrm{Cd}$. In ATR-FTIR spectrum of samples, it can be seen that the absorption intensity at about $450-800\left(\mathrm{~cm}^{-1}\right)$ related to creation of CdO nanoparticles increases as the temperature of ablation environment increases. By warming the human cancer cells, tissues and tumors, the number and variety of Oxygen and its radicals increase in the environment and it leads to emerging new Oxygen bonds in liquid environment as ATR-FTIR peak at $2360\left(\mathrm{~cm}^{-1}\right)$ is due to them.

Figure (7) shows the image of nanoparticles. Gold nanoparticles solution with purple color is a sign of existence of Gold nanoparticles with the size of $30(\mathrm{~nm})$. In addition, Cadmium Oxide $(\mathrm{CdO})$ solution is colorless. Transparency of the color of nanoparticles mixture after emission of synchrotron radiation with $532(\mathrm{~nm})$ wavelength indicates that the size of nanoparticles, especially Gold nanoparticles, vary in the solution which it can be attributed to the formation of alloy. Also, Figure (8) shows UV-Vis-NIR spectra for samples.

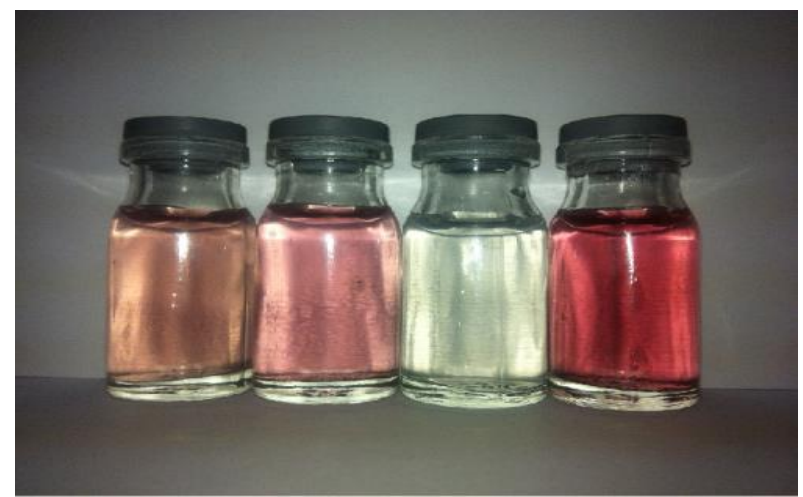

Fig. 7: From Right to Left: Gold Nanoparticles, Cadmium Oxide (CdO), Its Mixture before Laser Emission with Wavelength of $532(\mathrm{~nm})$ and Their Alloy.

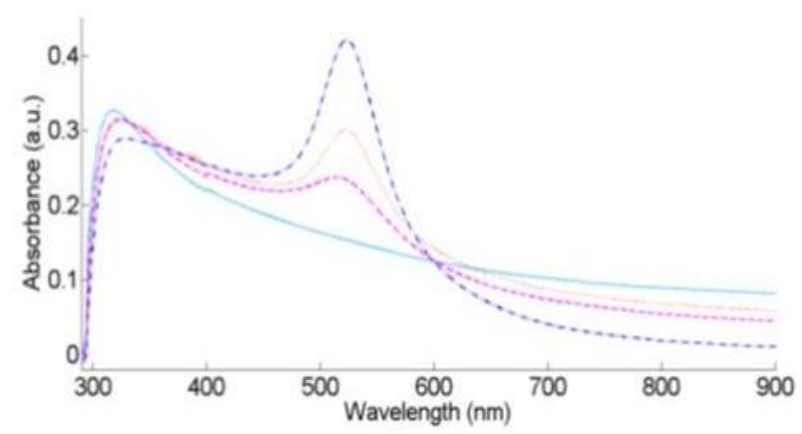

Fig. 8: UV-Vis-NIR Spectra for Samples.

This issue can be observed in absorption spectrum of nanoparticles. In this spectrum, Plasmon peak of Gold nanoparticles can be seen at about $523(\mathrm{~nm})$. In addition, exytoninc peak related to Cadmium Oxide $(\mathrm{CdO})$ nanoparticles is formed at $318(\mathrm{~nm})$. After mixing these two nanoparticles, both peaks descend which indicates that their density in the solution reduces and after synchrotron radiation emission of $532(\mathrm{~nm})$, Plasmon peak of Gold nanoparticles more reduces while exytonic peak of Cadmium Oxide $(\mathrm{CdO})$ does not changes. The location of Gold peak varies with a red shift of about $518(\mathrm{~nm})$ which indicates that Gold nanoparticles are enlarged in the compound. These processes have been reported in previous researches (Heidari 2016, 2017; Heidari and 
Brown 2017; Bastogne 2017; Vanić et al. 2013; Islan et al. 2017; Bawarski et al. 2008; Eaton et al. 2011; Hadinoto et al. 2014; Svenson et al. 2011; Sosnik et al. 2013; Filipović-Grčić et al. 2013; Yu et al. 2015; Moghimi et al. 2013; Eliasof et al. 2010; Domingo et al. 2012; Samadder et al. 2016; Yen et al. 2010; Azmi et al. 2016; L et al. 2015; Liu et al. 2012; Gabellieri et al. 2011; Frederickson 2016 et al; Namdari et al. 2017; Kiew et al. 2015; Moghimi et al. 2012; Gil et al. 2010; Rzigalinski et al. 2009; Fako et al. 2009; Sainz et al. 2015; Duncan et al. 2010; Zhou et al. 2014; Wibroe et al. 2016; Nguyen et al. 2016; Beija et al. 2012; Vaishali et al. 2017; Bawa 2009; Marianecci et al. 2016; Patil et al. 2017; Fonseca et al. 2014; Bedi et al. 2011; Canal et al. 2011; Hügel et al. 2014; Donaldson 2012; Bose et al. 2016; Hall et al. 2017; Storm 2012; du Toit et al. 2010; Kumar et al. 2016; Rajabi et al. 2016; Andersen et al. 2012; Kabanov et al. 2011; Nagy et al. 2015; Nickols-Richardson et al. 2007; Gaspar et al. 2009; Bourlinos et al. 2012; Svenson et al. 2012; Sitterberg et al. 2010; Telford 2005). The reason for this variation is in fact the formation of Gold and Cadmium Oxide (CdO) alloy which leads to increase in amplitude of vibrations of surface electrons of Gold nanoparticles. Figure (9) shows XRD spectrum of nanoparticles. To produce these spectra, some part of solution was dried over the silicon and then, spectroscopy was performed. The peak related to silicon is emerged at 69 degrees that is removed from the curves. In this figure, XRD spectra for Gold and Cadmium Oxide $(\mathrm{CdO})$ nanoparticles are shown along with those related to their mixture and alloy. A weak peak is emerged at 33 degrees in XRD spectrum of Cadmium Oxide ( $\mathrm{CdO})$ sample which is due to the presence of rutile structure in these nanoparticles. Moreover, three major peaks related to Gold (III) Oxide $\left(\mathrm{Au}_{2} \mathrm{O}_{3}\right)$ and Gold at 27, 33 and 38 degrees, respectively, can be seen in XRD spectrum of Gold nanoparticles. After mixing them, the peaks related to Gold are reduced in XRD spectrum. In this spectrum, the peak related to Cadmium Oxide $(\mathrm{CdO})$ and Gold nanoparticles are overlapped in 33 degrees. Reduction of the peak indicates that the amounts of Gold nanoparticles are reduced in the solution. As can be seen, the peak related to Gold (III) Oxide $\left(\mathrm{Au}_{2} \mathrm{O}_{3}\right)$ at 27 degrees is disappeared after synchrotron radiation emission of $532(\mathrm{~nm})$. Separation of Oxygen atoms from metal atoms such as Gold is due to melting of these metal nanoparticles during synchrotron radiation emission of $532(\mathrm{~nm})$. The common peak of Gold and Cadmium Oxide ( $\mathrm{CdO})$ nanoparticles at 33 degrees are considerably enhanced relative to mixture before synchrotron radiation emission which indicates that Gold and Cadmium alloy structure is formed and a new peak related to rutile phase of Cadmium Oxide $(\mathrm{CdO})$ nanoparticles at 29 degrees is emerged which indicates that lattice of these nanoparticles are changed due to synchrotron radiaiton emission of $532(\mathrm{~nm})$. Similar results have been reported in previous researches (Alibolandi et al. 2015; Bridoux et al. 2009; Stuurman et al. 2010; Kondo 2010; Jindal et al. 2017; Rapoport 2007; Fernández 2011; Pippa et al. 2013; Verreault et al. 2012; Hassanzadeh et al. 2017; Sivanesan et al. 2017; Phillips et al. 2010; Varan et al. 2017; Moghimi et al. 2014; Soria et al. 2010; McMurray et al. 2010; Sans-Serramitjana et al. 2016; Rigo et al. 2017; Alibolandi et al. 2017; Bridoux et al. 2010; Tutaj et al. 2016; Kuppusamy et al. 2013; Tomalia 2006; Menjoge et al. 2010; Vega-Villa et al. 2008; Gaur et al. 2014; Tietze et al. 2015; Schwengber et al. 2015; Adhikari et al. 2017; Szebeni et al. 2015; Chen et al. 2011; Requejo-Aguilar et al. 2017; Golyshkin et al. 2016; Szulc et al. 2016; Haddad et al. 2008; Mignani et al. 2013; Eaton et al. 2015; Lollo et al. 2015; Thompson et al. 2012; Muntimadugu et al. 2017; Foldvari et al. 2008; Riley et al. 2012; Fernandes et al. 2015; Mehra et al. 2016; Mignani et al. 2016; Naderkhani et al. 2014; Newton 2013; Aoki et al. 2015; Ita 2014; Liu et al. 2008; Mallapragada et al. 2015; Peres et al. 2017; Ferreira et al. 2013; Salerno et al. 2015; Tyler et al. 2016; Iannazzo et al. 2015; Jemec et al. 2012; Chen et al. 2012; Lütscher et al. 2012; Park et al. 2013; Huang et al. 2011; Depan et al. 2011; Guo et al. 2014; Duncan 2011; Sidik et al. 2016; Yuan et al. 2010; He et al. 2014; An et al. 2013; Meenach et al. 2013; England et al. 2012; Pippa et al. 2013; Boisseau et al. 2011; Petrichenko et al. 2015;
Rodríguez-Gascón et al. 2015; Frima et al. 2012; Yallapu et al. 2015; Duan et al. 2012; Perez et al. 2015; Costantino et al. 2012; Wei et al. 2006; Murday et al. 2009; Dixit et al. 2015; Nair et al. 2010; Bawa et al. 2005; Farkhani et al. 2014; Lal et al. 2010; Hacklin et al. 2009; Gabizon et al. 2016; Zhang et al. 2013; Vanić et al. 2014; Ellis-Behnke 2007; Srivalli et al. 2016; Collnot et al. 2012; Rychak et al. 2006; Watala et al. 2016; Palombo et al. 2009; Kuzmov et al. 2015; Diebold et al. 2010; Bal et al. 2011; Bharali et al. 2010; Ray et al. 2010; Mishra et al. 2010; Torchilin 2009; Cupaioli et al. 2014; Sosnik et al. 2014; Guan et al. 2013; Toit et al. 2013; Zhang et al. 2012; Muthaiyan et al. 2011; Duncan 2009; Palao-Suay et al. 2016; Morrow et al. 2007; Punetha et al. 2017; Manickam 2017; Osorio et al. 2015; Karami et al. 2016; Park et al. 2013; Heidari 2017, 2018; Gobato et al. 2018; Gobato, Heidari 2018; Heidari, Gobato 2018).

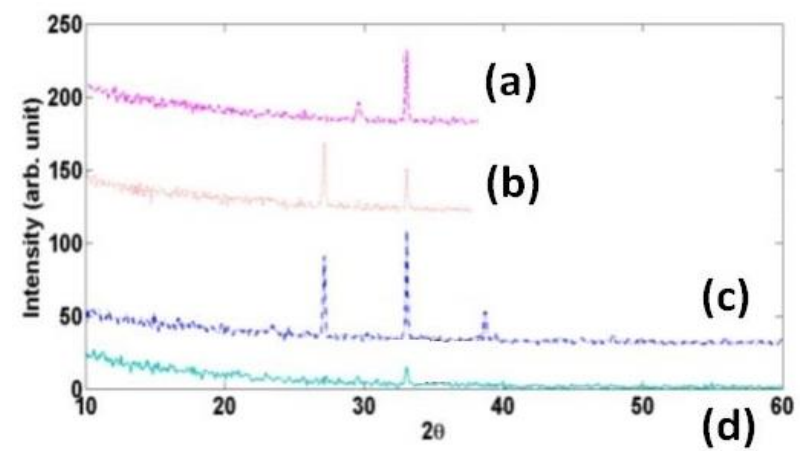

Fig. 9: XRD Spectra of Cadmium Oxide (CdO) Nanoparticles (a) before and (b) after Synchrotron Radiation and Gold Nanoparticles (a) before and (b) after Synchrotron Radiation Along with their Mixture before and after Synchrotron Radiation Emission with Wavelength of $532(\mathrm{~nm})$.

Figure (10) shows size distribution curves for nanoparticles measured by DLS technique. It should be noted that this mechanism shows hydrodynamic size of nanoparticles that is larger than real size of them but is proportional to real size. Hydrodynamic size is in fact the diameter of particle plus the diameter of electrostatic potential form adjacent to the particle. Figure (10) consists of four size distribution curves. In Figure 10 (a), Cadmium Oxide (CdO) size distribution is shown in which the peak is at $110(\mathrm{~nm})$. In Figure 10 (b), size distribution of Gold nanoparticles is shown which its peak is at $30(\mathrm{~nm})$. Size of particles before synchrotron radiation emission is shown in the third graph. As can be seen, Gold nanoparticles are frequent in the mixture and the peak size is approximately with the similar intensity that indicates larger number of these nanoparticles in the solution. However, after synchrotron radiation emission of $532(\mathrm{~nm})$, size of samples is completely changed in the solution. Nanoparticles with 30-40 (nm) size increase up to $80-100(\mathrm{~nm})$ and it is due to formation of alloy.
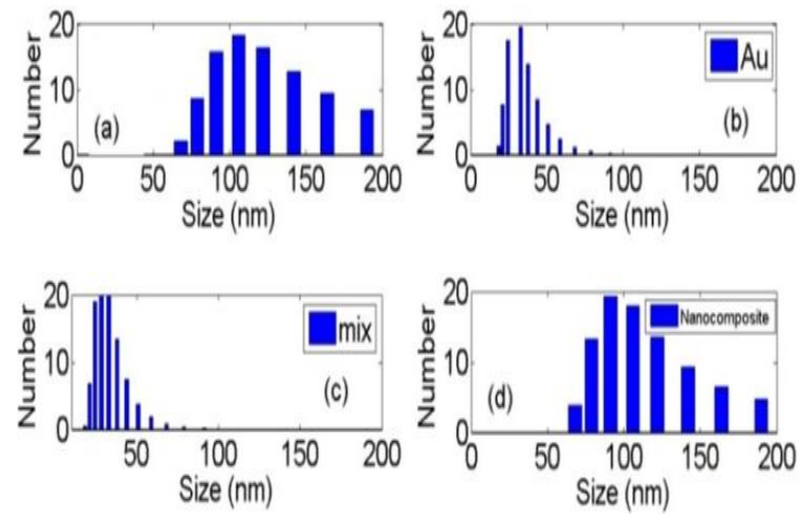

Fig. 10: Size Distribution Curve of Nanoparticles (a) Cadmium Oxide (CdO), (b) Gold, (c) Mixture of Gold and Cadmium Oxide (CdO) Nanoparticles before Synchrotron Radiation Emission and (d) Nanocomposite (Alloy) of Gold and Cadmium Oxide (CdO) Nanoparticles. 
(a)

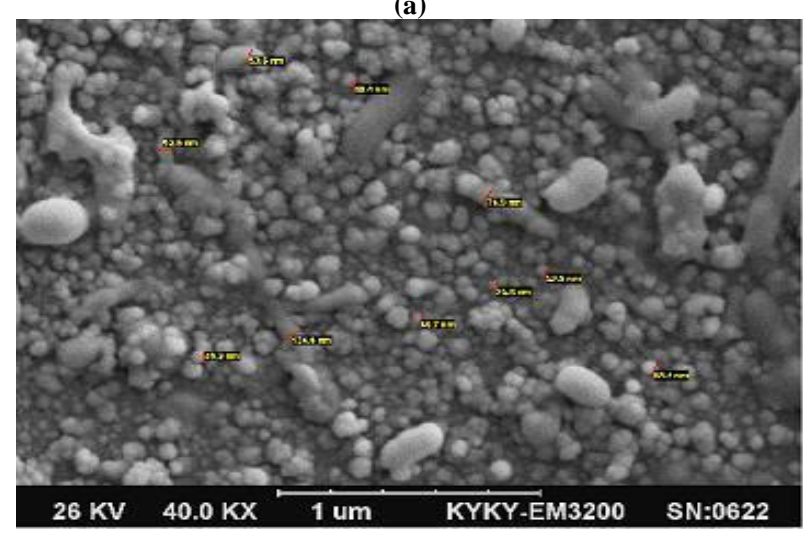

(b)

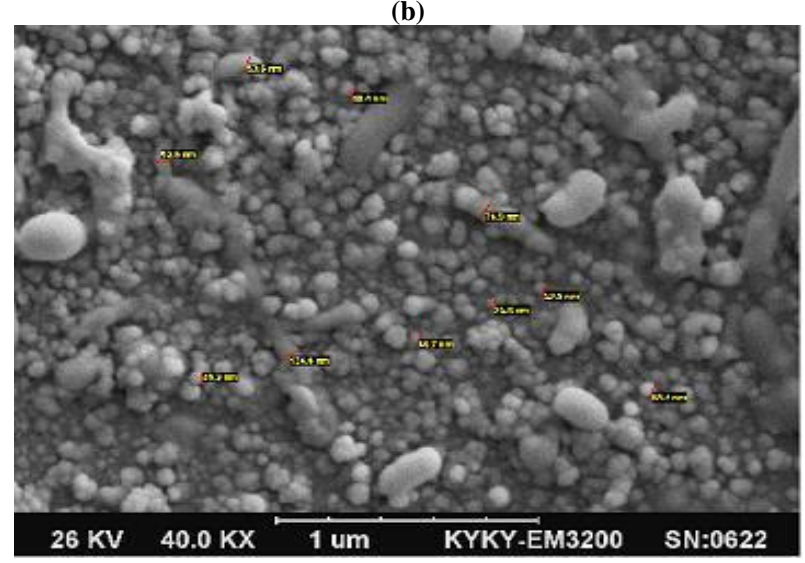

(c)

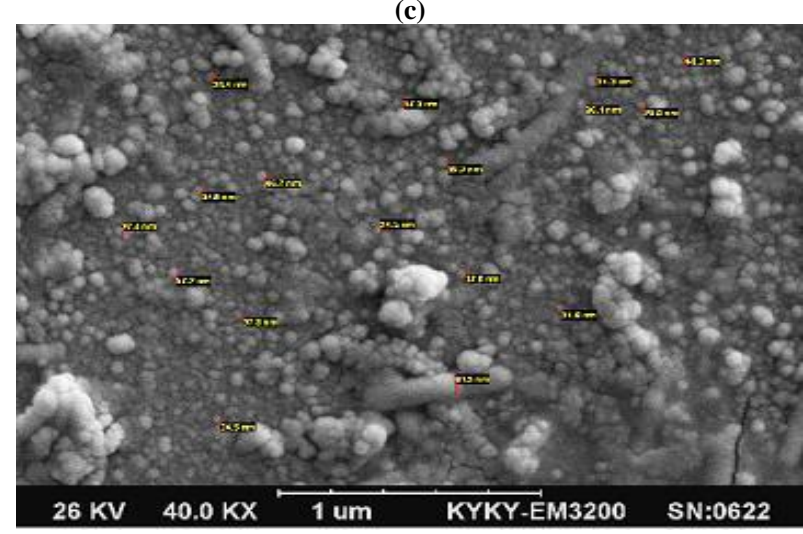

(d)

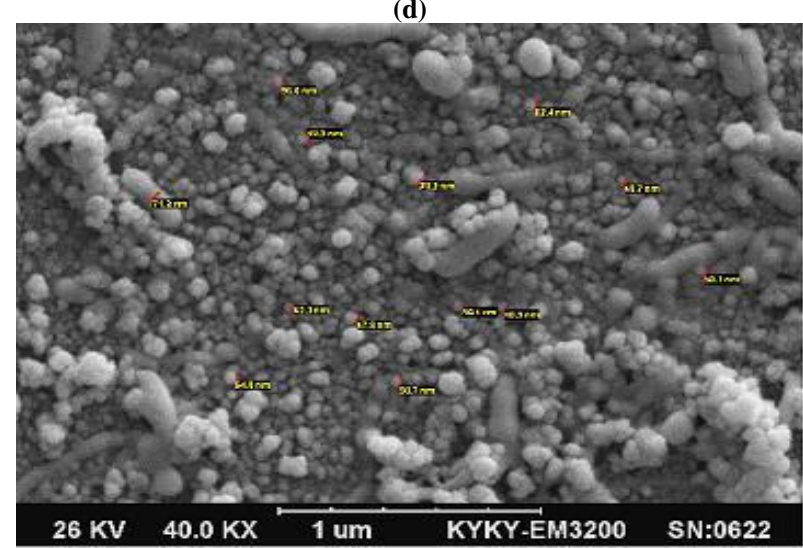

Fig. 11: SEM Images of Nanoparticles (a) Cadmium Oxide (CdO), (b) Gold, (c) Their Mixture and (d) Their Alloy Compound.
Figure (11) shows SEM images of nanoparticles. These images are taken with $26(\mathrm{keV})$ electrons and 40000-x zoom. Figure 11 (a) shows Cadmium Oxide (CdO) nanoparticles that some parts of them are spherical and fine and another part are ellipsoidal. Fine spherical particles are about $40-50(\mathrm{~nm})$ and coarse ellipsoidal ones are 80-100 (nm). Figure 11 (b) shows Gold nanoparticles images which are mostly spherical and are about 30-40 (nm). Their cohesion is very lower than Cadmium Oxide $(\mathrm{CdO})$ nanoparticles which are a characteristic of noble metal nanoparticles. Figure 11 (c) shows the images for the mixture. As Gold nanoparticles and most of Cadmium Oxide $(\mathrm{CdO})$ nanoparticles are spherical, this figure mainly consists of spherical particles. There is more cohesion between some of them which are Cadmium Oxide $(\mathrm{CdO})$ nanoparticles. The image of mixture after synchrotron radiaiton emission is shown in Figure 11 (d). Spherical nanoparticles with larger size than previous state can be seen in this figure. The presence of Gold and Cadmium Oxide (CdO) alloy can be attributed to this. The presence of more ellipsoidal particles is a sign of reduction in Gold nanoparticles and formation of alloy in this sample.

\section{Conclusion}

The experimental results show that nanoparticle sizes increase as the temperature of ablation environment increases. It can be attributed to variation of water density. When synchrotron radiation incidents to the target, the atoms of target separate from each other and plasma creates on the surface of target. Expansion of the plasma in liquid environment leads to distribution of shock waves toward the environment. The separated atoms from target are again bond together as a result of the pressure of these waves and create nanoparticles. The results show that nanoparticle size depends on the pressure and higher pressure leads to smaller nanoparticles. In the tests, increasing the temperature of human cancer cells, tissues and tumors reduces the water density and leads to decrease in pressure in plasma environment. This reduction leads to increase in size of nanoparticles. The effect of temperature of liquid environment on the nanoparticles has been observed in previous papers.

Furthermore, in the current experimental research, a 532 (nm) synchrotron radiation pulse was used to melt Gold nanoparticles in the mixture of Gold $(\mathrm{Au})$-Cadmium Oxide $(\mathrm{CdO})$ in the human cancer cells, tissues and tumors and to create an alloy (nanocomposite) from this mixture. The point used in this process is Plasmon resonance absorption peak of Gold nanoparticles at the vicinity of $532(\mathrm{~nm})$ which leads to absorption a large part of energy of synchrotron radiation by these nanoparticles which is the key point in production of the alloy. In addition, formation of alloy and its characteristics are observed by various devices.

\section{References}

[1] Heidari, A., Brown, C. (2015). Study of Composition and Morphology of Cadmium Oxide (CdO) Nanoparticles for Eliminating Cancer Cells, Journal of Nanomedicine Research, Volume 2, Issue 5, 20 Pages.

[2] Heidari, A., Brown, C. (2015). Study of Surface Morphological, Phytochemical and Structural Characteristics of Rhodium (III) Oxide $\left(\mathrm{Rh}_{2} \mathrm{O}_{3}\right)$ Nanoparticles, International Journal of Pharmacology, Phytochemistry and Ethnomedicine, Volume 1, Pages 15-19. https://doi.org/10.18052/www.scipress.com/IJPPE.1.15.

[3] Heidari, A. (2016). An Experimental Biospectroscopic Study on Seminal Plasma in Determination of Semen Quality for Evaluation of Male Infertility, Int J Adv Technol 7: e007. https://doi.org/10.4172/0976-4860.1000e007.

[4] Heidari, A. (2016). Extraction and Preconcentration of N-TolylSulfonyl-Phosphoramid-Saeure-Dichlorid as an Anti-Cancer Drug from Plants: A Pharmacognosy Study, J Pharmacogn Nat Prod 2: e103. https://doi.org/10.4172/2472-0992.1000e103.

[5] Heidari, A. (2016). A Thermodynamic Study on Hydration and Dehydration of DNA and RNA-Amphiphile Complexes, J Bioeng Biomed Sci S: 006. 
[6] Heidari, A. (2016). Computational Studies on Molecular Structures and Carbonyl and Ketene Groups' Effects of Singlet and Triplet Energies of Azidoketene $\mathrm{O}=\mathrm{C}=\mathrm{CH}-\mathrm{NNN}$ and Isocyanatoketene $\mathrm{O}=\mathrm{C}=\mathrm{CH}-\mathrm{N}=\mathrm{C}=\mathrm{O}, \mathrm{J}$ Appl Computat Math 5: e142.

[7] Heidari, A. (2016). Study of Irradiations to Enhance the Induces the Dissociation of Hydrogen Bonds between Peptide Chains and Transition from Helix Structure to Random Coil Structure Using ATRFTIR, Raman and ${ }^{1}$ HNMR Spectroscopies, J Biomol Res Ther 5: e146. https://doi.org/10.4172/2167-7956.1000e146.

[8] Heidari, A. (2016). Future Prospects of Point Fluorescence Spectroscopy, Fluorescence Imaging and Fluorescence Endoscopy in Photodynamic Therapy (PDT) for Cancer Cells, J Bioanal Biomed 8: e135. https://doi.org/10.4172/1948-593X.1000e135.

[9] Heidari, A. (2016). A Bio-Spectroscopic Study of DNA Density and Color Role as Determining Factor for Absorbed Irradiation in Cancer Cells, Adv Cancer Prev 1: e102. https://doi.org/10.4172/2472-0429.1000e102.

[10] Heidari, A. (2016). Manufacturing Process of Solar Cells Using Cadmium Oxide (CdO) and Rhodium (III) Oxide $\left(\mathrm{Rh}_{2} \mathrm{O}_{3}\right)$ Nanoparticles, J Biotechnol Biomater 6: e125. https://doi.org/10.4172/2155952X.1000e125.

[11] Heidari, A. (2016). a Novel Experimental and Computational Approach to Photobiosimulation of Telomeric DNA/RNA: A Biospectroscopic and Photobiological Study, J Res Development 4: 144.

[12] Heidari, A. (2016). Biochemical and Pharmacodynamical Study of Microporous Molecularly Imprinted Polymer Selective for Vancomycin, Teicoplanin, Oritavancin, Telavancin and Dalbavancin Binding, Biochem Physiol 5: e146. https://doi.org/10.4172/2168$9652.1000 \mathrm{e} 146$.

[13] Heidari, A. (2016). Anti-Cancer Effect of UV Irradiation at Presence of Cadmium Oxide (CdO) Nanoparticles on DNA of Cancer Cells: A Photodynamic Therapy Study, Arch Cancer Res. 4: 1 https://doi.org/10.21767/2254-6081.100061.

[14] Heidari, A. (2016). Biospectroscopic Study on Multi-Component Reactions (MCRs) in Two A-Type and B-Type Conformations of Nucleic Acids to Determine Ligand Binding Modes, Binding Constant and Stability of Nucleic Acids in Cadmium Oxide (CdO) Nanoparticles-Nucleic Acids Complexes as Anti-Cancer Drugs, Arch Cancer Res. 4: 2. https://doi.org/10.21767/2254-6081.100065.

[15] Heidari, A. (2016). Simulation of Temperature Distribution of DNA/RNA of Human Cancer Cells Using Time-Dependent BioHeat Equation and Nd: YAG Lasers, Arch Cancer Res. 4: 2. https://doi.org/10.21767/2254-6081.100069.

[16] Heidari, A. (2016). Quantitative Structure-Activity Relationship (QSAR) Approximation for Cadmium Oxide (CdO) and Rhodium (III) Oxide $\left(\mathrm{Rh}_{2} \mathrm{O}_{3}\right)$ Nanoparticles as Anti-Cancer Drugs for the Catalytic Formation of Proviral DNA from Viral RNA Using Multiple Linear and Non-Linear Correlation Approach, Ann Clin Lab Res. 4: 1. https://doi.org/10.21767/2386-5180.100076.

[17] Heidari, A. (2016). Biomedical Study of Cancer Cells DNA Therapy Using Laser Irradiations at Presence of Intelligent Nanoparticles, J Biomedical Sci. 5: 2. https://doi.org/10.4172/2254-609X.100023.

[18] Heidari, A. (2016). Measurement the Amount of Vitamin D2 (Ergocalciferol), Vitamin D3 (Cholecalciferol) and Absorbable Calcium $\left(\mathrm{Ca}^{2+}\right)$, Iron (II) $\left(\mathrm{Fe}^{2+}\right)$, Magnesium $\left(\mathrm{Mg}^{2+}\right)$, Phosphate $\left(\mathrm{PO}^{4-}\right)$ and Zinc $\left(\mathrm{Zn}^{2+}\right)$ in Apricot Using High-Performance Liquid Chromatography (HPLC) and Spectroscopic Techniques, J Biom Biostat 7: 292. https://doi.org/10.4172/2155-6180.1000292.

[19] Heidari, A. Spectroscopy and Quantum Mechanics of the Helium Dimer $\left(\mathrm{He}^{2+}\right)$, Neon Dimer $\left(\mathrm{Ne}^{2+}\right)$, Argon Dimer $\left(\mathrm{Ar}^{2+}\right)$, Krypton Dimer $\left(\mathrm{Kr}^{2+}\right)$, Xenon Dimer $\left(\mathrm{Xe}^{2+}\right)$, Radon Dimer $\left(\mathrm{Rn}^{2+}\right)$ and Ununoctium Dimer $\left(\mathrm{Uuo}^{2+}\right)$ Molecular Cations, Chem Sci J 7: e112, 2016. https://doi.org/10.4172/2150-3494.1000e112.

[20] Heidari, A. (2016). Human Toxicity Photodynamic Therapy Studies on DNA/RNA Complexes as a Promising New Sensitizer for the Treatment of Malignant Tumors Using Bio-Spectroscopic Techniques, J Drug Metab Toxicol 7: e129. https://doi.org/10.4172/2157-7609.1000e129.

[21] Heidari, A. (2016). Novel and Stable Modifications of Intelligent Cadmium Oxide (CdO) Nanoparticles as Anti-Cancer Drug in Formation of Nucleic Acids Complexes for Human Cancer Cells' Treatment, Biochem Pharmacol (Los Angel) 5: 207. https://doi.org/10.4172/2167-0501.1000207.

[22] Heidari, A. (2016). A Combined Computational and QM/MM Molecular Dynamics Study on Boron Nitride Nanotubes (BNNTs), Amorphous Boron Nitride Nanotubes (a-BNNTs) and Hexagonal Boron Nitride Nanotubes (h-BNNTs) as Hydrogen Storage, Struct Chem Crystallogr Commun 2: 1 .

[23] Heidari, A. (2016). Pharmaceutical and Analytical Chemistry Study of Cadmium Oxide $(\mathrm{CdO})$ Nanoparticles Synthesis Methods and
Properties as Anti-Cancer Drug and its Effect on Human Cancer Cells, Pharm Anal Chem Open Access 2: 113

[24] Heidari, A. (2016). A Chemotherapeutic and Biospectroscopic Investigation of the Interaction of Double-Standard DNA/RNABinding Molecules with Cadmium Oxide (CdO) and Rhodium (III) Oxide $\left(\mathrm{Rh}_{2} \mathrm{O}_{3}\right)$ Nanoparticles as Anti-Cancer Drugs for Cancer Cells' Treatment, Chemo Open Access 5: e129.

[25] Heidari, A. (2016). Pharmacokinetics and Experimental Therapeutic Study of DNA and Other Biomolecules Using Lasers: Advantages and Applications, J Pharmacokinet Exp Ther 1: e005.

[26] Heidari, A. (2016). Determination of Ratio and Stability Constant of DNA/RNA in Human Cancer Cells and Cadmium Oxide (CdO) Nanoparticles Complexes Using Analytical Electrochemical and Spectroscopic Techniques, Insights Anal Electrochem 2: 1.

[27] Heidari, A. (2016). Discriminate between Antibacterial and NonAntibacterial Drugs Artificial Neutral Networks of a Multilayer Perceptron (MLP) Type Using a Set of Topological Descriptors, J Heavy Met Toxicity Dis. 1: 2. https://doi.org/10.21767/24736457.100009.

[28] Heidari, A. (2016). Combined Theoretical and Computational Study of the Belousov-Zhabotinsky Chaotic Reaction and Curtius Rearrangement for Synthesis of Mechlorethamine, Cisplatin, Streptozotocin, Cyclophosphamide, Melphalan, Busulphan and BCNU as Anti-Cancer Drugs, Insights Med Phys. 1: 2.

[29] Heidari, A. (2016). A Translational Biomedical Approach to Structural Arrangement of Amino Acids' Complexes: A Combined Theoretical and Computational Study, Transl Biomed. 7: 2 https://doi.org/10.21767/2172-0479.100072.

[30] Heidari, A. (2016). Ab Initio and Density Functional Theory (DFT) Studies of Dynamic NMR Shielding Tensors and Vibrational Frequencies of DNA/RNA and Cadmium Oxide (CdO) Nanoparticles Complexes in Human Cancer Cells, J Nanomedine Biotherapeutic Discov 6: e144.

[31] Heidari, A. (2016). Molecular Dynamics and Monte-Carlo Simulations for Replacement Sugars in Insulin Resistance, Obesity, LDL Cholesterol, Triglycerides, Metabolic Syndrome, Type 2 Diabetes and Cardiovascular Disease: A Glycobiological Study, J Glycobiol 5: e111. https://doi.org/10.4172/2168-958X.1000e111.

[32] Heidari, A. (2016). Synthesis and Study of [5]-[(Phenylsulfonyl) Amino]-1, 3, 4-Thiadiazole-2-Sulfonamide as Potential AntiPertussis Drug Using Chromatography and Spectroscopy Techniques, Transl Med (Sunnyvale) 6: e138. https://doi.org/10.4172/2161-1025.1000e137.

[33] Heidari, A. (2016). Nitrogen, Oxygen, Phosphorus and Sulphur Heterocyclic Anti-Cancer Nano Drugs Separation in the Supercritical Fluid of Ozone $\left(\mathrm{O}_{3}\right)$ Using Soave-Redlich-Kwong (SRK) and Pang-Robinson (PR) Equations, Electronic J Biol 12: 4.

[34] Heidari, A. (2016). An Analytical and Computational Infrared Spectroscopic Review of Vibrational Modes in Nucleic Acids, Austin J Anal Pharm Chem. 3(1): 1058.

[35] Heidari, A., Brown, C. (2016). Phase, Composition and Morphology Study and Analysis of Os-Pd/HfC Nanocomposites, Nano Res Appl. 2: 1 .

[36] Heidari, A., Brown, C. (2016). Vibrational Spectroscopic Study of Intensities and Shifts of Symmetric Vibration Modes of Ozone Diluted by Cumene, International Journal of Advanced Chemistry, 4 (1) 5-9. https://doi.org/10.14419/ijac.v4i1.6080.

[37] Heidari, A. (2016). Study of the Role of Anti-Cancer Molecules with Different Sizes for Decreasing Corresponding Bulk Tumor Multiple Organs or Tissues, Arch Can Res. 4: 2. https://doi.org/10.21767/2254-6081.100083.

[38] Heidari, A. (2016). Genomics and Proteomics Studies of Zolpidem, Necopidem, Alpidem, Saripidem, Miroprofen, Zolimidine, Olprinone and Abafungin as Anti-Tumor, Peptide Antibiotics, Antiviral and Central Nervous System (CNS) Drugs, J Data Mining Genomics \& Proteomics 7: e125. https://doi.org/10.4172/2153$0602.1000 \mathrm{e} 125$.

[39] Heidari, A. (2016). Pharmacogenomics and Pharmacoproteomics Studies of Phosphodiesterase-5 (PDE5) Inhibitors and Paclitaxel Albumin-Stabilized Nanoparticles as Sandwiched Anti-Cancer Nano Drugs between Two DNA/RNA Molecules of Human Cancer Cells, J Pharmacogenomics Pharmacoproteomics 7: e153. https://doi.org/10.4172/2153-0645.1000e153.

[40] Heidari, A. (2016). Biotranslational Medical and Biospectroscopic Studies of Cadmium Oxide (CdO) Nanoparticles-DNA/RNA Straight and Cycle Chain Complexes as Potent Anti-Viral, AntiTumor and Anti-Microbial Drugs: A Clinical Approach, Transl Biomed. 7: 2. https://doi.org/10.21767/2172-0479.100076.

[41] Heidari, A. (2016). A Comparative Study on Simultaneous Determination and Separation of Adsorbed Cadmium Oxide (CdO) Na- 
noparticles on DNA/RNA of Human Cancer Cells Using Biospectroscopic Techniques and Dielectrophoresis (DEP) Method, Arch Can Res. 4: 2. https://doi.org/10.21767/2254-6081.100086.

[42] Heidari, A. (2016). Cheminformatics and System Chemistry of Cisplatin, Carboplatin, Nedaplatin, Oxaliplatin, Heptaplatin and Lobaplatin as Anti-Cancer Nano Drugs: A Combined Computational and Experimental Study, J Inform Data Min 1: 3. https://doi.org/10.21767/2472-1956.100015.

[43] Heidari, A. (2016). Linear and Non-Linear Quantitative StructureAnti-Cancer-Activity Relationship (QSACAR) Study of Hydrous Ruthenium (IV) Oxide $\left(\mathrm{RuO}_{2}\right)$ Nanoparticles as Non-Nucleoside Reverse Transcriptase Inhibitors (NNRTIs) and Anti-Cancer Nano Drugs, J Integr Oncol 5: e110.

[44] Heidari, A. (2016). Synthesis, Characterization and Biospectroscopic Studies of Cadmium Oxide (CdO) Nanoparticles-Nucleic Acids Complexes Absence of Soluble Polymer as a Protective Agent Using Nucleic Acids Condensation and Solution Reduction Method, J Nanosci Curr Res 1: e101.

[45] Heidari, A. (2016). Coplanarity and Collinearity of 4'-Dinonyl2,2'-Bithiazole in One Domain of Bleomycin and Pingyangmycin to be Responsible for Binding of Cadmium Oxide (CdO) Nanoparticles to DNA/RNA Bidentate Ligands as Anti-Tumor Nano Drug, Int J Drug Dev \& Res 8: 007-008.

[46] Heidari, A. (2016). A Pharmacovigilance Study on Linear and Non-Linear Quantitative Structure (Chromatographic) Retention Relationships (QSRR) Models for the Prediction of Retention Time of Anti-Cancer Nano Drugs under Synchrotron Radiations, J Pharmacovigil 4: e161. https://doi.org/10.4172/2329. $6887.1000 \mathrm{e} 161$.

[47] Heidari, A. (2016). Nanotechnology in Preparation of Semipermeable Polymers, J Adv Chem Eng 6: 157 https://doi.org/10.4172/2090-4568.1000e108.

[48] Heidari, A. (2016). A Gastrointestinal Study on Linear and NonLinear Quantitative Structure (Chromatographic) Retention Relationships (QSRR) Models for Analysis 5-Aminosalicylates Nano Particles as Digestive System Nano Drugs under Synchrotron Radiations, J Gastrointest Dig Syst 6: e119. https://doi.org/10.4172/2161-069X.1000e119.

[49] Heidari, A. (2016). DNA/RNA Fragmentation and Cytolysis in Human Cancer Cells Treated with Diphthamide Nano Particles Derivatives, Biomedical Data Mining 5: e102.

[50] Heidari, A. (2016). A Successful Strategy for the Prediction of Solubility in the Construction of Quantitative Structure-Activity Relationship (QSAR) and Quantitative Structure-Property Relationship (QSPR) under Synchrotron Radiations Using Genetic Function Approximation (GFA) Algorithm, J Mol Biol Biotechnol 1: 1.

[51] Heidari, A. (2016). Computational Study on Molecular Structures of $\mathrm{C}_{20}, \mathrm{C}_{60}, \mathrm{C}_{240}, \mathrm{C}_{540}, \mathrm{C}_{960}, \mathrm{C}_{2160}$ and $\mathrm{C}_{3840}$ Fullerene Nano Molecules under Synchrotron Radiations Using Fuzzy Logic, J Material Sci Eng 5: 282. https://doi.org/10.4172/2169-0022.1000282.

[52] Heidari, A. (2016). Graph Theoretical Analysis of Zigzag Polyhexamethylene Biguanide, Polyhexamethylene Adipamide, Polyhexamethylene Biguanide Gauze and Polyhexamethylene Biguanide Hydrochloride (PHMB) Boron Nitride Nanotubes (BNNTs), Amorphous Boron Nitride Nanotubes (a-BNNTs) and Hexagona Boron Nitride Nanotubes (h-BNNTs), J Appl Computat Math 5: e143. https://doi.org/10.4172/2168-9679.1000e143.

[53] Heidari, A. (2016). The Impact of High Resolution Imaging on Diagnosis, Int J Clin Med Imaging 3: 1000e101

[54] Heidari, A. (2016). A Comparative Study of Conformational Behavior of Isotretinoin (13-Cis Retinoic Acid) and Tretinoin (AllTrans Retinoic Acid (ATRA)) Nano Particles as Anti-Cancer Nano Drugs under Synchrotron Radiations Using Hartree-Fock (HF) and Density Functional Theory (DFT) Methods, Insights in Biomed 1: 2.

[55] Heidari, A. (2016). Advances in Logic, Operations and Computational Mathematics, J Appl Computat Math 5: 5 https://doi.org/10.4172/2168-9679.1000e144.

[56] Heidari, A. (2016). Mathematical Equations in Predicting Physical Behavior, J Appl Computat Math 5: 5 https://doi.org/10.4172/2168-9679.1000e145.

[57] Heidari, A. (2016). Chemotherapy a Last Resort for Cancer Treatment, Chemo Open Access 5: 4. https://doi.org/10.4172/2167$7700.1000 \mathrm{e} 130$.

[58] Heidari, A. (2016). Separation and Pre-Concentration of Metal Cations-DNA/RNA Chelates Using Molecular Beam Mass Spectrometry with Tunable Vacuum Ultraviolet (VUV) Synchrotron Radiation and Various Analytical Methods, Mass Spectrom Purif Tech 2 e101. https://doi.org/10.4172/2469-9861.1000e101.
[59] Heidari, A. (2016). Yoctosecond Quantitative Structure-Activity Relationship (QSAR) and Quantitative Structure-Property Relationship (QSPR) under Synchrotron Radiations Studies for Prediction of Solubility of Anti-Cancer Nano Drugs in Aqueous Solutions Using Genetic Function Approximation (GFA) Algorithm, Insight Pharm Res. 1: 1

[60] Heidari, A. (2016). Cancer Risk Prediction and Assessment in $\mathrm{Hu}-$ man Cells under Synchrotron Radiations Using Quantitative Structure Activity Relationship (QSAR) and Quantitative Structure Properties Relationship (QSPR) Studies, Int J Clin Med Imaging 3: 516. https://doi.org/10.4172/2376-0249.1000516.

[61] Heidari, A. (2016). A Novel Approach to Biology, Electronic J Biol 12: 4.

[62] Heidari, A. (2016). Innovative Biomedical Equipment's for Diagnosis and Treatment, $\mathrm{J}$ Bioengineer \& Biomedical Sci 6: 2 https://doi.org/10.4172/2155-9538.1000e124.

[63] Heidari, A. (2016). Integrating Precision Cancer Medicine into Healthcare, Medicare Reimbursement Changes and the Practice of Oncology: Trends in Oncology Medicine and Practices, J Oncol Med \& Pract 1: 2.

[64] Heidari, A. (2016). Promoting Convergence in Biomedical and Biomaterials Sciences and Silk Proteins for Biomedical and Biomaterials Applications: An Introduction to Materials in Medicine and Bioengineering Perspectives, J Bioengineer \& Biomedical Sci 6: 3. https://doi.org/10.4172/2155-9538.1000e126.

[65] Heidari, A. (2017). X-Ray Fluorescence and X-Ray Diffraction Analysis on Discrete Element Modeling of Nano Powder Metallurgy Processes in Optimal Container Design, J Powder Metall Min 6 :

[66] Heidari, A. (2017). Biomolecular Spectroscopy and Dynamics of Nano-Sized Molecules and Clusters as Cross-Linking-Induced Anti-Cancer and Immune-Oncology Nano Drugs Delivery in DNA/RNA of Human Cancer Cells' Membranes under Synchrotron Radiations: A Payload-Based Perspective, Arch Chem Res. 1: 2. https://doi.org/10.21767/2572-4657.100011.

[67] Heidari, A. (2017). Deficiencies in Repair of Double-Standard DNA/RNA-Binding Molecules Identified in Many Types of Solid and Liquid Tumors Oncology in Human Body for Advancing Cancer Immunotherapy Using Computer Simulations and Data Analysis, J Appl Bioinforma Comput Biol, 6: 1. https://doi.org/10.4172/2329-9533.1000e104.

[68] Heidari, A. (2017). Electronic Coupling among the Five Nanomolecules Shuts Down Quantum Tunneling in the Presence and Absence of an Applied Magnetic Field for Indication of the Dimer or other Provide Different Influences on the Magnetic Behavior of Single Molecular Magnets (SMMs) as Qubits for Quantum Computing, Glob J Res Rev. 4: 2. https://doi.org/10.4172/23299533.1000e104.

[69] Heidari, A. (2017). Polymorphism in Nano-Sized Graphene Ligand-Induced Transformation of $\mathrm{Au}_{38}-\mathrm{xAg}_{\mathrm{x}} / \mathrm{xCu}_{\mathrm{x}}(\mathrm{SPh}-\mathrm{tBu})_{24}$ to $\mathrm{Au}_{36}-\mathrm{xAg}_{\mathrm{x}} / \mathrm{xCu} \mathrm{u}_{\mathrm{x}}(\mathrm{SPh}-\mathrm{tBu})_{24}(\mathrm{x}=1-12)$ Nanomolecules for Synthesis of $\mathrm{Au}_{144}-\mathrm{xAg}_{\mathrm{x}} / \mathrm{xCu}_{\mathrm{x}}\left[(\mathrm{SR})_{60},\left(\mathrm{SC}_{4}\right)_{60},\left(\mathrm{SC}_{6}\right)_{60},\left(\mathrm{SC}_{12}\right)_{60},(\mathrm{PET})_{60}\right.$ $(\mathrm{p}-\mathrm{MBA})_{60},(\mathrm{~F})_{60},(\mathrm{Cl})_{60},(\mathrm{Br})_{60},(\mathrm{I})_{60},(\mathrm{At})_{60},(\mathrm{Uus})_{60}$ and $\left(\mathrm{SC}_{6} \mathrm{H}_{13}\right)_{60}$ Nano Clusters as Anti-Cancer Nano Drugs, J Nanomater Mol Nanotechnol, 6: 3. https://doi.org/10.4172/2324-8777.1000109e.

[70] Heidari, A. (2017). Biomedical Resource Oncology and Data Mining to Enable Resource Discovery in Medical, Medicinal, Clinical, Pharmaceutical, Chemical and Translational Research and Their Applications in Cancer Research, Int J Biomed Data Min 6: e103. https://doi.org/10.4172/2090-4924.1000e103.

[71] Heidari, A. (2017). Study of Synthesis, Pharmacokinetics, Pharmacodynamics, Dosing, Stability, Safety and Efficacy of Olympiadane Nanomolecules as Agent for Cancer Enzymotherapy, Immunotherapy, Chemotherapy, Radiotherapy, Hormone Therapy and Targeted Therapy under Synchrotorn Radiation, J Dev Drugs 6: e154. https://doi.org/10.4172/2329-6631.1000e154.

[72] Heidari, A. (2017). A Novel Approach to Future Horizon of Top Seven Biomedical Research Topics to Watch in 2017: Alzheimer's, Ebola, Hypersomnia, Human Immunodeficiency Virus (HIV), Tuberculosis (TB), Microbiome/Antibiotic Resistance and Endovascular Stroke, J Bioengineer \& Biomedical Sci 7: e127. https://doi.org/10.4172/2155-9538.1000e127.

[73] Heidari, A. (2017). Opinion on Computational Fluid Dynamics (CFD) Technique, Fluid Mech Open Acc 4: 157. https://doi.org/10.4172/2476-2296.1000157.

[74] Heidari, A. (2017). Concurrent Diagnosis of Oncology Influence Outcomes in Emergency General Surgery for Colorectal Cancer and Multiple Sclerosis (MS) Treatment Using Magnetic Resonance Imaging $(\mathrm{MRI})$ and $\mathrm{Au}_{329}(\mathrm{SR})_{84}, \quad \mathrm{Au}_{329-\mathrm{x}} \mathrm{Ag}_{\mathrm{x}}(\mathrm{SR})_{84}$ $\mathrm{Au}_{144}(\mathrm{SR})_{60}, \quad \mathrm{Au}_{68}(\mathrm{SR})_{36}, \quad \mathrm{Au}_{30}(\mathrm{SR})_{18}, \quad \mathrm{Au}_{102}(\mathrm{SPh})_{44}, \mathrm{Au}_{38}(\mathrm{SPh})_{24}$ 
$\mathrm{Au}_{38}\left(\mathrm{SC}_{2} \mathrm{H}_{4} \mathrm{Ph}\right)_{24}, \quad \mathrm{Au}_{21} \mathrm{~S}(\mathrm{SAdm})_{15}, \quad \mathrm{Au}_{36}(\mathrm{pMBA})_{24} \quad$ and $\mathrm{Au}_{25}(\mathrm{pMBA})_{18}$ Nano Clusters, J Surgery Emerg Med 1: 21.

[75] Heidari, A. (2017). Developmental Cell Biology in Adult Stem Cells Death and Autophagy to Trigger a Preventive Allergic Reaction to Common Airborne Allergens under Synchrotron Radiation Using Nanotechnology for Therapeutic Goals in Particular Allergy Shots (Immunotherapy), Cell Biol (Henderson, NV) 6: 1 .

[76] Heidari, A. (2017). Changing Metal Powder Characteristics for Elimination of the Heavy Metals Toxicity and Diseases in Disruption of Extracellular Matrix (ECM) Proteins Adjustment in Cancer Metastases Induced by Osteosarcoma, Chondrosarcoma, Carcinoid, Carcinoma, Ewing's Sarcoma, Fibrosarcoma and Secondary Hematopoietic Solid or Soft Tissue Tumors, J Powder Metall Min 6: 170 https://doi.org/10.4172/2168-9806.1000170.

[77] Heidari, A. (2017). Nanomedicine-Based Combination AntiCancer Therapy between Nucleic Acids and Anti-Cancer Nano Drugs in Covalent Nano Drugs Delivery Systems for Selective Imaging and Treatment of Human Brain Tumors Using Hyaluronic Acid, Alguronic Acid and Sodium Hyaluronate as Anti-Cancer Nano Drugs and Nucleic Acids Delivery under Synchrotron Radiation, Am J Drug Deliv 5: 2. https://doi.org/10.21767/2321547X.1000016.

[78] Heidari, A. (2017). Clinical Trials of Dendritic Cell Therapies for Cancer Exposing Vulnerabilities in Human Cancer Cells' Metabolism and Metabolomics: New Discoveries, Unique Features Inform New Therapeutic Opportunities, Biotech's Bumpy Road to the Market and Elucidating the Biochemical Programs that Support Cancer Initiation and Progression, J Biol Med Science 1: e103.

[79] Heidari, A. (2017). The Design Graphene-Based Nanosheets as a New Nanomaterial in Anti-Cancer Therapy and Delivery of Chemotherapeutics and Biological Nano Drugs for Liposomal Anti-Cancer Nano Drugs and Gene Delivery, Br Biomed Bull 5: 305.

[80] Heidari, A. (2017). Integrative Approach to Biological Networks for Emerging Roles of Proteomics, Genomics and Transcriptomics in the Discovery and Validation of Human Colorectal Cancer Biomarkers from DNA/RNA Sequencing Data under Synchrotron Radiation, Transcriptomics 5: e117. https://doi.org/10.4172/2329$8936.1000 \mathrm{e} 117$

[81] Heidari, A. (2017). Elimination of the Heavy Metals Toxicity and Diseases in Disruption of Extracellular Matrix (ECM) Proteins and Cell Adhesion Intelligent Nanomolecules Adjustment in Cancer Metastases Using Metalloenzymes and under Synchrotron Radiation, Lett Health Biol Sci 2 (2): 1-4. https://doi.org/10.15436/24756245.17.019.

[82] Heidari, A. (2017). Treatment of Breast Cancer Brain Metastases through a Targeted Nanomolecule Drug Delivery System Based on Dopamine Functionalized Multi-Wall Carbon Nanotubes (MWCNTs) Coated with Nano Graphene Oxide (GO) and Protonated Polyaniline (PANI) in Situ During the Polymerization of Aniline Autogenic Nanoparticles for the Delivery of Anti-Cancer Nano Drugs under Synchrotron Radiation, Br J Res, 4(3): 16 https://doi.org/10.21767/2394-3718.100016.

[83] Heidari, A. (2017). Sedative, Analgesic and Ultrasound-Mediated Gastrointestinal Nano Drugs Delivery for Gastrointestinal Endoscopic Procedure, Nano Drug-Induced Gastrointestinal Disorders and Nano Drug Treatment of Gastric Acidity, Res Rep Gastroenterol, $1: 1$

[84] Heidari, A. (2017). Synthesis, Pharmacokinetics, Pharmacodynamics, Dosing, Stability, Safety and Efficacy of Orphan Nano Drugs to Treat High Cholesterol and Related Conditions and to Prevent Cardiovascular Disease under Synchrotron Radiation, J Pharm Sci Emerg Drugs 5: 1. https://doi.org/10.4172/2380$9477.1000 \mathrm{e} 104$

[85] Heidari, A. (2017). Non-Linear Compact Proton Synchrotrons to Improve Human Cancer Cells and Tissues Treatments and Diagnostics through Particle Therapy Accelerators with Monochromatic Microbeams, J Cell Biol Mol Sci 2(1): 1-5.

[86] Heidari, A. (2017). Design of Targeted Metal Chelation Therapeutics Nanocapsules as Colloidal Carriers and Blood-Brain Barrier (BBB) Translocation to Targeted Deliver Anti-Cancer Nano Drugs into the Human Brain to Treat Alzheimer's Disease under Synchrotron Radiation, J Nanotechnol Material Sci 4(2): 1-5.

[87] Gobato, R., Heidari, A. (2017). Calculations Using Quantum Chemistry for Inorganic Molecule Simulation $\mathrm{BeLi}_{2} \mathrm{SeSi}$, American Journal of Quantum Chemistry and Molecular Spectroscopy, Vol. 2, No. 3, Pages 37-46.

[88] Heidari, (2017). A. Different High-Resolution Simulations of Medical, Medicinal, Clinical, Pharmaceutical and Therapeutics Oncology of Human Lung Cancer Translational Anti-Cancer Nano Drugs
Delivery Treatment Process under Synchrotron and X-Ray Radiations, J Med Oncol. Vol. 1 No. 1: 1 .

[89] Heidari, A. (2017). A Modern Ethnomedicinal Technique for Transformation, Prevention and Treatment of Human Malignant Gliomas Tumors into Human Benign Gliomas Tumors under Synchrotron Radiation, Am J Ethnomed, Vol. 4 No. 1: 10. https://doi.org/10.21767/2348-9502.100010.

[90] Heidari, A. (2014). An Investigation of the Role of DNA as Molecular Computers: A Computational Study on the Hamiltonian Path Problem, International Journal of Scientific \& Engineering Research, Vol. 5, Issue 1, Pages 1884-1889.

[91] Heidari, A. (2017). Active Targeted Nanoparticles for Anti-Cancer Nano Drugs Delivery across the Blood-Brain Barrier for Human Brain Cancer Treatment, Multiple Sclerosis (MS) and Alzheimer's Diseases Using Chemical Modifications of Anti-Cancer Nano Drugs or Drug-Nanoparticles through Zika Virus (ZIKV) Nanocarriers under Synchrotron Radiation, J Med Chem Toxicol, 2(3): 1-5 https://doi.org/10.15436/2575-808X.17.1594.

[92] Heidari, A. (2017). Investigation of Medical, Medicinal, Clinical and Pharmaceutical Applications of Estradiol, Mestranol (Norlutin), Norethindrone (NET), Norethisterone Acetate (NETA), Norethisterone Enanthate (NETE) and Testosterone Nanoparticles as Biological Imaging, Cell Labeling, Anti-Microbial Agents and Anti-Cancer Nano Drugs in Nanomedicines Based Drug Delivery Systems for Anti-Cancer Targeting and Treatment, Parana Journal of Science and Education (PJSE)-V.3, n.4, (10-19) October 12.

[93] Heidari, A. (2017). A Comparative Computational and Experimental Study on Different Vibrational Biospectroscopy Methods, Techniques and Applications for Human Cancer Cells in Tumor Tissues Simulation, Modeling, Research, Diagnosis and Treatment, Open J Anal Bioanal Chem 1(1): 014-020.

[94] Heidari, A. (2017). Combination of DNA/RNA Ligands and Linear/Non-Linear Visible-Synchrotron Radiation-Driven N-Doped Ordered Mesoporous Cadmium Oxide (CdO) Nanoparticles Photocatalysts Channels Resulted in an Interesting Synergistic Effect Enhancing Catalytic Anti-Cancer Activity, Enz Eng 6: 1.

[95] Heidari, A. (2017). Modern Approaches in Designing Ferritin, Ferritin Light Chain, Transferrin, Beta-2 Transferrin and Bacterioferritin-Based Anti-Cancer Nano Drugs Encapsulating Nanosphere as DNA-Binding Proteins from Starved Cells (DPS), Mod Appro Drug Des. 1(1). MADD.000504.

[96] Heidari, A. (2017). Potency of Human Interferon $\beta-1 \mathrm{a}$ and Human Interferon $\beta-1 \mathrm{~b}$ in Enzymotherapy, Immunotherapy, Chemotherapy, Radiotherapy, Hormone Therapy and Targeted Therapy of Encephalomyelitis Disseminate/Multiple Sclerosis (MS) and Hepatitis A, B, C, D, E, F and G Virus Enter and Targets Liver Cells, J Proteomics Enzymol 6: 1. https://doi.org/10.4172/2470$1289.1000 \mathrm{e} 109$.

[97] Heidari, A. (2017). Transport Therapeutic Active Targeting of Human Brain Tumors Enable Anti-Cancer Nanodrugs Delivery across the Blood-Brain Barrier (BBB) to Treat Brain Diseases Using Nanoparticles and Nanocarriers under Synchrotron Radiation, J Pharm Pharmaceutics 4(2): 1-5.

[98] Heidari, A., Brown, C. (2017). Combinatorial Therapeutic Approaches to DNA/RNA and Benzylpenicillin (Penicillin G), Fluoxetine Hydrochloride (Prozac and Sarafem), Propofol (Diprivan), Acetylsalicylic Acid (ASA) (Aspirin), Naproxen Sodium (Aleve and Naprosyn) and Dextromethamphetamine Nanocapsules with Surface Conjugated DNA/RNA to Targeted Nano Drugs for Enhanced Anti-Cancer Efficacy and Targeted Cancer Therapy Using Nano Drugs Delivery Systems, Ann Adv Chem. 1(2): 061-069.

[99] Heidari, A. (2016). Vibrational Spectroscopy of Nucleic Acids, Wahid Ali Khan (Editor), Basic Biochemistry, Austin Publishing Group (APG)/Austin Publications LLC, ISBN: 978-0-9971499-20 , Pages 1-18, Jersey City, New Jersey, USA.

[100] Heidari, A. (2017). High-Resolution Simulations of Human Brain Cancer Translational Nano Drugs Delivery Treatment Process under Synchrotron Radiation, J Transl Res 1(1): 1-3.

[101] Bastogne, T. (2017). Quality-by-design of nanopharmaceuticals - a state of the art, Nanomedicine: Nanotechnology, Biology and Medicine, https://doi.org/10.1016/j.nano.2017.05.014.

[102] Vanić, Ž. Škalko-Basnet, N. (2013). Nanopharmaceuticals for improved topical vaginal therapy: Can they deliver?, European Journal of Pharmaceutical Sciences, Volume 50, Issue 1, Pages 2941, ISSN 0928-0987,. https://doi.org/10.1016/j.ejps.2013.04.035.

[103] Islan, G. A., Durán, M., Cacicedo, M. L., Nakazato, G., Kobayashi, R. K. T., Martinez, D. S. T., Castro, G. R., Durán, N. (2017). Nanopharmaceuticals as a solution to neglected diseases: Is it pos- 
sible?, Acta Tropica, Volume 170, Pages 16-42, ISSN 0001-706X, https://doi.org/10.1016/j.actatropica.2017.02.019.

[104] Bawarski, W. E., Chidlowsky, E., Bharali, D. J., Mousa, S. A (2008). Emerging nanopharmaceuticals, Nanomedicine: Nanotechnology, Biology and Medicine, Volume 4, Issue 4, Pages 273-282. ISSN 1549-9634, https://doi.org/10.1016/j.nano.2008.06.002.

[105] Eaton, M. A. W. (2011). How do we develop nanopharmaceuticals under open innovation?, Nanomedicine: Nanotechnology, Biology and Medicine, Volume 7, Issue 4, Pages 371-375, ISSN 1549-9634, https://doi.org/10.1016/j.nano.2011.05.015.

[106] Hadinoto, K., Yang, Y. (2014). Continuous and sustainable granulation of nanopharmaceuticals by spray coagulation encapsulation in alginate, International Journal of Pharmaceutics, Volume 473, Issue 1, Pages 644-652, ISSN 0378-5173, https://doi.org/10.1016/j.ijpharm.2014.07.042.

[107] Svenson, S., Wolfgang, M., Hwang, J., Ryan, J., Eliasof, S (2011). Preclinical to clinical development of the novel camptothecin nanopharmaceutical CRLX101, Journal of Controlled Release, Volume 153, Issue 1, Pages 49-55, ISSN 0168-3659, https://doi.org/10.1016/j.jconrel.2011.03.007.

[108] Sosnik, A. (2013). Reversal of multidrug resistance by the inhibition of ATP-binding cassette pumps employing Generally Recognized As Safe (GRAS) nanopharmaceuticals: A review, Advanced Drug Delivery Reviews, Volume 65, Issue 13, Pages 1828-1851, ISSN 0169-409X, https://doi.org/10.1016/j.addr.2013.09.002.

[109] Filipović-Grčić, J., Mrhar, A., Junginger, H. (2013). Thematic Issue on Emerging nanopharmaceuticals for non-parenteral application routes, European Journal of Pharmaceutical Sciences, Volume 50, Issue 1, Page 1, ISSN 0928-0987, https://doi.org/10.1016/j.ejps.2013.05.025.

[110] Yu, H., Hadinoto, K. (2015). Mitigating the adverse effect of spray drying on the supersaturation generation capability of amorphous nanopharmaceutical powders, Powder Technology, Volume 277, Pages 97-104, ISSN 0032-5910, https://doi.org/10.1016/j.powtec.2015.02.059.

[111] Moghimi, S. M., Farhangrazi, Z. S. (2013). Nanomedicine and the complement paradigm, Nanomedicine: Nanotechnology, Biology and Medicine, Volume 9, Issue 4, Pages 458-460, ISSN 15499634, https://doi.org/10.1016/j.nano.2013.02.011.

[112] Eliasof, S., Ng, P. S., Soo, P. L., Podobinski, J., Case, R. I., Shum, P., Martinez, J. G., Kabir, S. R., Lazarus, D., Svenson, S. (2010). 425 Significantly enhanced therapeutic profile of docetaxel in novel nanopharmaceutical CRLX288, European Journal of Cancer Supplements, Volume 8, Issue 7, Page 135, ISSN 1359-6349, https://doi.org/10.1016/S1359-6349(10)72132-7.

[113] Domingo, C., Saurina, J. (2012). An overview of the analytical characterization of nanostructured drug delivery systems: Towards green and sustainable pharmaceuticals: A review, Analytica Chimica Acta, Volume 744, Pages 8-22, ISSN 0003-2670, https://doi.org/10.1016/j.aca.2012.07.010.

[114] Samadder, A., Abraham, S. K., Khuda-Bukhsh, A. R. (2016) Nanopharmaceutical approach using pelargonidin towards enhancement of efficacy for prevention of alloxan-induced DNA damage in L6 cells via activation of PARP and p53, Environmental Toxicology and Pharmacology, Volume 43, Pages 27-37, ISSN 1382-6689, https://doi.org/10.1016/j.etap.2016.02.010.

[115] Yen, Y., Synold, T., Weiss, G. J., Schluep, T., Ryan, J. (2010). 423 Phase 1 dose escalation, safety and pharmacokinetic study of IT-101 (CRLX101), a novel nanopharmaceutical containing camptothecin, in advanced solid tumor cancer patients, European Journal of Cancer Supplements, Volume 8, Issue 7, Pages 134-135, ISSN 1359-6349, https://doi.org/10.1016/S1359-6349(10)72130-3.

[116] Azmi, I. D. M., Wibroe, P. P., Wu, L. P., Kazem, A. I., Amenitsch, H., Moghimi, S. M., Yaghmur, A. (2016). A structurally diverse library of safe-by-design citrem-phospholipid lamellar and non-lamellar liquid crystalline nano-assemblies, Journal of Controlled Release, Volume 239, Pages 1-9, ISSN 0168-3659, https://doi.org/10.1016/j.jconrel.2016.08.011.

[117] Li, J., Wang, Y., Liang, R., an, X., Wang, K., Shen, G., Tu, Y., Zhu, J., Tao, J. (2015). Recent advances in targeted nanoparticles drug delivery to melanoma, Nanomedicine: Nanotechnology, Biology and Medicine, Volume 11, Issue 3, Pages 769-794, ISSN 15499634,. https://doi.org/10.1016/j.nano.2014.11.006.

[118] Liu, J., Zhao, Y., Guo, Q., Wang, Z., Wang, H., Yang, Y., Huang, Y. (2012). TAT-modified nanosilver for combating multidrug-resistant cancer, Biomaterials, Volume 33, Issue 26, Pages 6155-6161, ISSN https://doi.org/10.1016/j.biomaterials.2012.05.035.

[119] Gabellieri, C., Frima, H. (2011). Nanomedicine in the European Commission policy for nanotechnology, Nanomedicine: Nanotech- nology, Biology and Medicine, Volume 7, Issue 5, Pages 519-520, ISSN 1549-9634, https://doi.org/10.1016/j.nano.2011.07.003.

[120] Frederickson, R. M., Moghimi, S. M., Wagner, E., YlaHerttuala, S. (2016). Call for papers: Nanoparticle Development and Applications in Cellular and Molecular Therapies, Molecular Therapy, Volume 24, Issue 8, Pages 1334-1335, ISSN 1525-0016, https://doi.org/10.1038/mt.2016.164.

[121] Namdari, M., Eatemadi, A., Soleimaninejad, M., Hammed, A. T., (2017). A brief review on the application of nanoparticle enclosed herbal medicine for the treatment of infective endocarditis, Biomedicine \& Pharmacotherapy, Volume 87, Pages 321-331, ISSN 0753-3322, https://doi.org/10.1016/j.biopha.2016.12.099.

[122] Kiew, T. Y., Cheow, W. S., Hadinoto, K. (2015). Preserving the supersaturation generation capability of amorphous drugpolysaccharide nanoparticle complex after freeze-drying, International Journal of Pharmaceutics, Volume 484, Issue 1, Pages 115 123, ISSN 0378-5173, https://doi.org/10.1016/j.ijpharm.2015.02.057.

[123] Moghimi, S. M., Wibroe, P. P., Helvig, S. Y., Farhangrazi, Z. S., Hunter, A. C. (2012). Genomic perspectives in inter-individual adverse responses following nanomedicine administration: The way forward, Advanced Drug Delivery Reviews, Volume 64, Issue 13, Pages 1385-1393, ISSN 0169-409X.

[124] Gil, P. R., Hühn, D., Del Mercato, L. L., Sasse, D., Parak, W. J. (2010). Nanopharmacy: Inorganic nanoscale devices as vectors and active compounds, Pharmacological Research, Volume 62, Issue 2, Pages 115-125, ISSN 1043-6618, https://doi.org/10.1016/i.phrs.2010.01.009.

[125] Rzigalinski, B. A., Strobl, J. S. (2009). Cadmium-containing nanoparticles: Perspectives on pharmacology and toxicology of quantum dots, Toxicology and Applied Pharmacology, Volume 238, Issue 3, Pages 280-288, ISSN 0041-008X, http://dx.doi.org/10.1016/j.taap.2009.04.010.

[126] Fako, V. E., Furgeson, D. Y. (2009). Zebrafish as a correlative and predictive model for assessing biomaterial nanotoxicity, Advanced Drug Delivery Reviews, Volume 61, Issue 6, Pages 478486 , ISSN

0169-409X http://dx.doi.org/10.1016/j.addr.2009.03.008

[127] Sainz, V., Conniot, J., Matos, A. I., Peres, C., Zupanǒiǒ, E., Moura, L., Silva, L. C., Florindo, H. F., Gaspar, R. S. (2015). Regulatory aspects on nanomedicines, Biochemical and Biophysical Research Communications, Volume 468, Issue 3, Pages 504-510, ISSN 0006-291X, http://dx.doi.org/10.1016/j.bbrc.2015.08.023.

[128] Duncan, R., Vicent, M. J., (2010). Do HPMA copolymer conjugates have a future as clinically useful nanomedicines? A critical overview of current status and future opportunities, Advanced Drug Delivery Reviews, Volume 62, Issue 2, Pages 272-282, ISSN 0169409X, http://dx.doi.org/10.1016/j.addr.2009.12.005.

[129] Zhou, X., Che, L., Wei, Y., Dou, Y., Chen, S., He, H., Gong, H., Li, X., Zhang, J. (2014). Facile route to versatile nanoplatforms for drug delivery by one-pot self-assembly, Acta Biomaterialia, Volume 10, Issue 6, Pages 2630-2642, ISSN 1742-7061,

[130] Wibroe, P. P., Ahmadvand, D., Oghabian, M. A., Yaghmur, A. Moghimi, S. M. (2016). An integrated assessment of morphology, size, and complement activation of the PEGylated liposomal doxorubicin products Doxil®, Caelyx $®$, DOXOrubicin, and SinaDoxosome, Journal of Controlled Release, Volume 221, Pages 1-8, ISSN 0168-3659, http://dx.doi.org/10.1016/j.jconrel.2015.11.021.

[131] Nguyen, M. H., Yu, H., Dong, B., Hadinoto, K. (2016). A supersaturating delivery system of silibinin exhibiting high payload achieved by amorphous nano-complexation with chitosan, European Journal of Pharmaceutical Sciences, Volume 89, Pages 163-171, ISSN 0928-0987, http://dx.doi.org/10.1016/j.ejps.2016.04.036.

[132] Special Issue Title Page, Biotechnology Advances, Volume 32, Issue 4, 2014, Page iii, ISSN 0734-9750, http://dx.doi.org/10.1016/S0734-9750(14)00084-6.

[133] Beija, M., Salvayre, R., Viguerie, N. L., Marty, J. D. (2012). Colloidal systems for drug delivery: from design to therapy, Trends in Biotechnology, Volume 30, Issue 9, Pages 485-496, ISSN $0167-$ 7799, http://dx.doi.org/10.1016/j.tibtech.2012.04.008.

[134] Vaishali, A., Varma, K. M., Bhupathi, P. A., Bharath, T. S. Ramesh, M. V., Varma, P. V. K. (2017). In vitro evaluation of antimicrobial efficacy of $2 \%$ chlorhexidine loaded electrospun nanofibers, Journal of Pierre Fauchard Academy (India Section), ISSN 0970-2199, http://dx.doi.org/10.1016/j.jpfa.2017.01.006.

[135] Bawa, R. (2009). NanoBiotech 2008: Exploring global advances in nanomedicine, Nanomedicine: Nanotechnology, Biology and Medicine, Volume 5, Issue 1, Pages 5-7, ISSN 1549-9634, http://dx.doi.org/10.1016/j.nano.2009.01.004. 
[136] Marianecci, C., Petralito, S., Rinaldi, F., Hanieh, P. N., Carafa M. (2016). Some recent advances on liposomal and niosomal vesicular carriers, Journal of Drug Delivery Science and Technology, Volume 32, Pages 256-269, ISSN 1773-2247, http://dx.doi.org/10.1016/j.jddst.2015.10.008.

[137] Patil, S., Chaudhari, K., Kamble, R. (2017). Electrospray technique for cocrystallization of phytomolecules, Journal of King Saud University - $\quad$ Science, $\quad$ ISSN $1018-3647$, http://dx.doi.org/10.1016/j.jksus.2017.04.001

[138] Fonseca, N. A., Gregório, A. C., Valério-Fernandes, Â, Simões, S., Moreira, J. N. (2014). Bridging cancer biology and the patients' needs with nanotechnology-based approaches, Cancer Treatment Reviews, Volume 40, Issue 5, Pages 626-635, ISSN 0305-7372.

[139] Bedi, D., Musacchio, T., Fagbohun, O. A., Gillespie, J. W., Deinnocentes, P., Bird, R. C., Bookbinder, L., Torchilin, V. P. Petrenko, V. A. (2011). Delivery of siRNA into breast cancer cells via phage fusion protein-targeted liposomes, Nanomedicine: Nanotechnology, Biology and Medicine, Volume 7, Issue 3, Pages 315 323, ISSN 1549-9634

[140] Canal, F., Sanchis, J., Vicent, M. J. (2011). Polymer-drug conjugates as nano-sized medicines, Current Opinion in Biotechnology, Volume 22, Issue 6, Pages 894-900, ISSN 0958-1669.

[141] Hügel, H. M., Jackson, N. (2014). Danshen diversity defeating dementia, Bioorganic \& Medicinal Chemistry Letters, Volume 24, Issue 3, Pages 708-716, ISSN 0960-894X.

[142] Special Issue title page, European Journal of Pharmaceutics and Biopharmaceutics, Volume 79, Issue 1, Page v, ISSN 0939-6411, http://dx.doi.org/10.1016/S0939-6411(11)00237-2.

[143] Donaldson, L. (2012). Designer nanoparticles to treat blood cancer, Materials Today, Volume 15, Issue 7, Page 298, ISSN 1369-7021.

[144] Graphical Abstracts, Journal of Fluorine Chemistry, Volume 198, 2017, Pages v-viii, ISSN 0022-1139.

[145] Bose, R. J. C., Lee, S. H., Park, H. (2016). Biofunctionalized nanoparticles: an emerging drug delivery platform for various disease treatments, Drug Discovery Today, Volume 21, Issue 8, Pages 1303-1312, ISSN 1359-6446.

[146] Hall, A., Lächelt, U., Bartek, J., Wagner, E., Moghimi, S. M. (2017). Polyplex Evolution: Understanding Biology, Optimizing Performance, Molecular Therapy, Volume 25, Issue 7, Pages 1476 1490, ISSN 1525-0016.

[147] Storm, G. (2012). Preface, European Journal of Pharmaceutical Sciences, Volume 45, Issue 4, Page 387, ISSN 0928-0987.

[148] Table of Contents, Acta Pharmaceutica Sinica B, Volume 7, Issue 3, 2017, Pages iii-vii, ISSN 2211-3835.

[149] Du Toit, L. C., Pillay, V., Choonara, Y. E. (2010). Nanomicrobicides: Challenges in drug delivery, patient ethics and intellectual property in the war against HIV/AIDS, Advanced Drug Delivery Reviews, Volume 62, Issue 4, Pages 532-546, ISSN 0169. 409X.

[150] Kumar, B., Angulo, Y., Smita, K., Cumbal, L., Debut, A. (2016). Capuli cherry-mediated green synthesis of silver nanoparticles under white solar and blue LED light, Particuology, Volume 24, Pages 123-128, ISSN 1674-2001.

[151] Rajabi, M., Sudha, T., Darwish, N. H. E., Davis, P. J., Mousa, S. A. (2016). Synthesis of MR-49, a deiodinated analog of tetraiodothyroacetic acid (tetrac), as a novel pro-angiogenesis modulator, Bioorganic \& Medicinal Chemistry Letters, Volume 26, Issue 16, Pages 4112-4116, ISSN 0960-894X.

[152] Andersen, A. J., Wibroe, P. P., Moghimi, S. M. (2012). Perspectives on carbon nanotube-mediated adverse immune effects, Advanced Drug Delivery Reviews, Volume 64, Issue 15, Pages 1700-1705, ISSN 0169-409X.

[153] Subject Index Volume 153, Journal of Controlled Release, Volume 153, Issue 3, 2011, Pages e8-e9, ISSN 0168-3659.

[154] Kabanov, A., Bronich, T. (2011). Eighth International Nanomedicine and Drug Delivery Symposium (NanoDDS'10), Journal of Controlled Release, Volume 153, Issue 1, Page 1, ISSN 0168-3659.

[155] Nagy, Z. K., Balogh, A., Démuth, B., Pataki, H., Vigh, T., Szabó, B., Molnár, K., Schmidt, B. T., Horák, P., Marosi, G., Verreck, G., Assche, I. V., Brewster, M. E. (2015). High speed electrospinning for scaled-up production of amorphous solid dispersion of itraconazole, International Journal of Pharmaceutics, Volume 480, Issue 1, Pages 137-142, ISSN 0378-5173.

[156] Nickols-Richardson, S. M. (2007). Nanotechnology: Implications for Food and Nutrition Professionals, Journal of the American Dietetic Association, Volume 107, Issue 9, Pages 1494-1497, ISSN 0002-8223.

[157] Gaspar, R., Duncan, R. (2009). Polymeric carriers: Preclinical safety and the regulatory implications for design and developmen of polymer therapeutics, Advanced Drug Delivery Reviews, Volume 61, Issue 13, Pages 1220-1231, ISSN 0169-409X.

[158] Graphical Abstracts Contents Listing, Journal of Controlled Release, Volume 153, Issue 1, 2011, Pages e1-e4, ISSN 0168-3659.

[159] Bourlinos, A. B., Georgakilas, V., Bakandritsos, A., Kouloumpis, A., Gournis, D., Zboril, R. (2012). Aqueous-dispersible fullerol-carbon nanotube hybrids, Materials Letters, Volume 82, Pages 48-50, ISSN 0167-577X.

[160] Recommended Articles, Journal of Acupuncture and Meridian Studies, Volume 9, Issue 6, 2016, Pages 345-348, ISSN 2005-2901.

[161] Svenson, S. (2012). Clinical translation of nanomedicines, Current Opinion in Solid State and Materials Science, Volume 16, Issue 6, Pages 287-294, ISSN https://doi.org/10.1016/j.cossms.2012.10.001.

[162] Sitterberg, J., Özcetin, A., Ehrhardt, C., Bakowsky, U. (2010). Utilising atomic force microscopy for the characterisation of nanoscale drug delivery systems, European Journal of Pharmaceutics and Biopharmaceutics, Volume 74, Issue 1, Pages 2-13, ISSN 0939-6411

[163] Telford, M. (2005). Cancer centers founded, Materials Today, Volume 8, Issue 12, Page 19, ISSN 1369-7021.

[164] Alibolandi, M., Sadeghi, F., Abnous, K., Atyabi, F., Ramezani, M., Hadizadeh, F. (2015). The chemotherapeutic potential of doxorubicin-loaded PEG-b-PLGA nanopolymersomes in mouse breast cancer model, European Journal of Pharmaceutics and Biopharmaceutics, Volume 94, Pages 521-531, ISSN 0939-6411.

[165] Bridoux, A., Cui, H., Dyskin, E., Yalcin, M., Mousa, S. A. (2009). Semisynthesis and pharmacological activities of Tetrac analogs: Angiogenesis modulators, Bioorganic \& Medicinal Chemistry Letters, Volume 19, Issue 12, Pages 3259-3263, ISSN 0960-894X.

[166] Stuurman, F. E., Voest, E. E., Awada, A., Schellens, J. H. M., Witteveen, P. O., Bergeland, T., Hals, P. A., Hendlisz, A. (2010) 426 Phase I study of oral CP-4126, a gemcitabine analog, in patients with advanced solid tumours, European Journal of Cancer Supplements, Volume 8, Issue 7, Page 135, ISSN 1359-6349.

[167] Kondo, E. (2010). 424 Development of novel cancer cellselective cell-penetrating peptides for the advanced peptide-based drug delivery system, European Journal of Cancer Supplements, Volume 8, Issue 7, Page 135, ISSN 1359-6349.

[168] Recommended Articles, Journal of Acupuncture and Meridian Studies, Volume 9, Issue 5, 2016, Pages 281-284, ISSN 2005-2901.

[169] Jindal, A. B., Bachhav, S. S., Devarajan, P. V. (2017). hybrid nano drug delivery system (IHN-DDS) of antiretroviral drug for simultaneous targeting to multiple viral reservoirs: An proof of concept, International Journal of Pharmaceutics, Volume 521, Issue 1, Pages 196-203, ISSN 0378-5173.

[170] Rapoport, N. (2007). Physical stimuli-responsive polymeric micelles for anti-cancer drug delivery, Progress in Polymer Science, Volume 32, Issue 8, Pages 962-990, ISSN 0079-6700.

[171] Fernández, L. Á. (2011). Muyldermans, S. Recent developments in engineering and delivery of protein and antibody therapeutics, Current Opinion in Biotechnology, Volume 22, Issue 6, Pages 839-842, ISSN 0958-1669.

[172] Pippa, N., Dokoumetzidis, A., Demetzos, C., Macheras, P. (2013). On the ubiquitous presence of fractals and fractal concepts in pharmaceutical sciences: A review, International Journal of Pharmaceutics, Volume 456, Issue 2, Pages 340-352, ISSN 03785173.

[173] Verreault, M., Strutt, D., Masin, D., Anantha, M., Waterhouse, D., Yapp, D. T., Bally, M. B. (2012). Irinophore CTM, a lipid-based nanoparticulate formulation of irinotecan, is more effective than free irinotecan when used to treat an orthotopic glioblastoma model, Journal of Controlled Release, Volume 158, Issue 1, Pages 3443, ISSN 0168-3659.

[174] Hassanzadeh, P., Atyabi, F., Dinarvand, R. (2017). Application of modelling and nanotechnology-based approaches: The emergence of breakthroughs in theranostics of central nervous system disorders, Life Sciences, Volume 182, Pages 93-103, ISSN 00243205.

[175] Sivanesan, S., Tan, A., Jeyaraj, R., Lam, J., Gole, M., Hardan, A., Ashkan, K., Rajadas, J. (2017). Pharmaceuticals and Stem Cells in Autism Spectrum Disorders: Wishful Thinking?, World Neurosurgery, Volume 98, Pages 659-672, ISSN 1878-8750.

[176] Phillips, R., Makeen, H., Periasamy, N., Loadman, P., Smye, S., Sleeman, B., Jones, P., Evans, C., Twelves, C. (2010). 427 The development and evaluation of an experimental model for assessing convective fluid flow through multicell layers, European Journal of Cancer Supplements, Volume 8, Issue 7, Pages 135-136, ISSN 1359-6349. 
[177] Varan, G., Varan, C., Erdoğar, N., Hıncal, A. A., Bilensoy, E. (2017). Amphiphilic cyclodextrin nanoparticles, International Journal of Pharmaceutics, ISSN 0378-5173.

[178] Moghimi, S. M., Farhangrazi, Z. S. (2014). Just so stories: The random acts of anti-cancer nanomedicine performance, Nanomedicine: Nanotechnology, Biology and Medicine, Volume 10, Issue 8, Pages 1661-1666, ISSN 1549-9634.

[179] Soria, J.C., Gomez-Roca, C.A., Ware, J.A., Adjei, A.A., Brachmann, R.K., Groen, H.J.M. (2010). 421 A Phase Ib study to evaluate the pan-PI3K inhibitor GDC-0941 with paclitaxel and carboplatin with and without bevacizumab in non-small cell lung cancer patients, European Journal of Cancer Supplements, Volume 8, Issue 7, Page 134, ISSN 1359-6349.

[180] McMurray, J., Klostergaard, J., Auzenne, E.J., Liao, W.S.L., Lu, Z., Mandal, P.K., Ramesh, R., Shanker, M., Scott, A.W. (2010). 422 Targeting the $\mathrm{SH} 2$ domain of Stat 3 with phosphopeptide mimetic prodrugs leads to tumor growth inhibition and downregulation of phosphoTyr705 Stat3 and angiogenic pathways, European Journal of Cancer Supplements, Volume 8, Issue 7, Page 134, ISSN 1359-6349.

[181] Sans-Serramitjana, E., Fusté, E., Martínez-Garriga, B., Merlos, A., Pastor, M., Pedraz, J.L., Esquisabel, A., Bachiller, D., Vinuesa T., Viñas, M. (2016). Killing effect of nanoencapsulated colistin sulfate on from cystic fibrosis patients, Journal of Cystic Fibrosis, Volume 15, Issue 5, Pages 611-618, ISSN 1569-1993.

[182] Rigo, L. A., Carvalho-Wodarz, C. S., Pohlmann, A. R., Guterres, S. S., Schneider-Daum, N., Lehr, C. M., Beck, R. C. R. (2017). Nanoencapsulation of a glucocorticoid improves barrier function and anti-inflammatory effect on monolayers of pulmonary epithelial cell lines, European Journal of Pharmaceutics and Biopharmaceutics, Volume 119, Pages 1-10, ISSN 0939-6411.

[183] Alibolandi, M., Taghdisi, S. M., Ramezani, P., Shamili, F. H., Farzad, S. A., Abnous, K., Ramezani, M. (2017). Smart AS1411aptamer conjugated pegylated PAMAM dendrimer for the superior delivery of camptothecin to colon adenocarcinoma and, International Journal of Pharmaceutics, Volume 519, Issue 1, Pages 352 364, ISSN 0378-5173.

[184] Bridoux, A., Cui, H., Dyskin, E., Schmitzer, A. R., Yalcin, M., Mousa, S. A. (2010). Semisynthesis and pharmacological activities of thyroxine analogs: Development of new angiogenesis modulators, Bioorganic \& Medicinal Chemistry Letters, Volume 20, Issue 11, Pages 3394-3398, ISSN 0960-894X.

[185] Tutaj, K., Szlazak, R., Szalapata, K., Starzyk, J., Luchowski, R., Grudzinski, W., Osinska-Jaroszuk, M., Jarosz-Wilkolazka, A., Szuster-Ciesielska, A., Gruszecki, W. I. (2016). Amphotericin Bsilver hybrid nanoparticles: synthesis, properties and antifungal activity, Nanomedicine: Nanotechnology, Biology and Medicine, Volume 12, Issue 4, Pages 1095-1103, ISSN 1549-9634.

[186] Kuppusamy, P., Yusoff, M. M., Maniam, G. P., Govindan, N. (2013). A case study - Regulation and functional mechanisms of cancer cells and control its activity using plants and their derivatives, Journal of Pharmacy Research, Volume 6, Issue 8, Pages 884 892, ISSN 0974-6943.

[187] Tomalia, D. A. (2006). International report on nanomedicine in the U.S.A., Nanomedicine: Nanotechnology, Biology and Medicine, Volume 2, Issue 4, Page 299, ISSN 1549-9634.

[188] Menjoge, A. R., Kannan, R. M., Tomalia, D. A. (2010). Dendrimer-based drug and imaging conjugates: design considerations for nanomedical applications, Drug Discovery Today, Volume 15, Issue 5, Pages 171-185, ISSN 1359-6446.

[189] Vega-Villa, K. R., Takemoto, J. K., Yáñez, J. A., Remsberg, C. M., Forrest, M. L., Davies, N. M. (2008). Clinical toxicities of nanocarrier systems, Advanced Drug Delivery Reviews, Volume 60, Issue 8, Pages 929-938, ISSN 0169-409X.

[190] Gaur, S., Wang, Y., Kretzner, L., Chen, L., Yen, T., Wu, X., Yuan, Y. C., Davis, M., Yen, Y. (2014). Pharmacodynamic and pharmacogenomic study of the nanoparticle conjugate of camptothecin CRLX101 for the treatment of cancer, Nanomedicine: Nanotechnology, Biology and Medicine, Volume 10, Issue 7, Pages 1477-1486, ISSN 1549-9634.

[191] Tietze, R., Zaloga, J., Unterweger, H., Lyer, S., Friedrich, R. P., Janko, C., Pöttler, M., Dürr, S., Alexiou, C. (2015). Magnetic nanoparticle-based drug delivery for cancer therapy, Biochemical and Biophysical Research Communications, Volume 468, Issue 3, Pages 463-470, ISSN 0006-291X.

[192] Schwengber, A., Prado, H. J., Zilli, D. A., Bonelli, P. R., Cukierman, A. L. (2015). Carbon nanotubes buckypapers for potential transdermal drug delivery, Materials Science and Engineering: C, Volume 57, Pages 7-13, ISSN 0928-4931.
[193] Adhikari, P., Pal, P., Das, A. K., Ray, S., Bhattacharjee, A., Mazumder, B. (2017). NANO LIPID-DRUG CONJUGATE: AN INTEGRATED REVIEW, International Journal of Pharmaceutics, ISSN 0378-5173, http://dx.doi.org/10.1016/j.ijpharm.2017.07.039.

[194] Szebeni, J., Storm, G. (2015). Complement activation as a bioequivalence issue relevant to the development of generic liposomes and other nanoparticulate drugs, Biochemical and Biophysical Research Communications, Volume 468, Issue 3, Pages 490-497, ISSN 0006-291X.

[195] Chen, K., Guan, J. (2011). A bibliometric investigation of research performance in emerging nanobiopharmaceuticals, Journal of Informetrics, Volume 5, Issue 2, Pages 233-247, ISSN 17511577.

[196] Requejo-Aguilar, R., Alastrue-Agudo, A., Cases-Villar, M., Lopez-Mocholi, E., England, R., Vicent, M. J., Moreno-Manzano, V. (2017). Combined polymer-curcumin conjugate and ependymal progenitor/stem cell treatment enhances spinal cord injury functional recovery, Biomaterials, Volume 113, Pages 18-30, ISSN 0142-9612.

[197] Golyshkin, D., Kobyliak, N., Virchenko, O., Falalyeyeva, T., Beregova, T., Ostapchenko, L., Caprnda, M., Skladany, L., Opatrilova, R., Rodrigo, L., Kruzliak, P., Shcherbokov, A., Spivak, M. (2016). Nanocrystalline cerium dioxide efficacy for prophylaxis of erosive and ulcerative lesions in the gastric mucosa of rats induced by stress, Biomedicine \& Pharmacotherapy, Volume 84, Pages 1383-1392, ISSN 0753-3322.

[198] Szulc, A., Pulaski, L., Appelhans, D., Voit, B., KlajnertMaculewicz, B. (2016). Sugar-modified poly(propylene imine) dendrimers as drug delivery agents for cytarabine to overcome drug resistance, International Journal of Pharmaceutics, Volume 513, Issue 1, Pages 572-583, ISSN 0378-5173.

[199] Haddad, P. S., Martins, T. M., D'Souza-Li, L., Li, L. M., Metze, K., Adam, R. L., Knobel, M., Zanchet, D. (2008). Structural and morphological investigation of magnetic nanoparticles based on iron oxides for biomedical applications, Materials Science and Engineering: C, Volume 28, Issue 4, Pages 489-494, ISSN 0928-4931.

[200] Mignani, S., El Kazzouli, S., Bousmina, M., Majoral, J. P. (2013). Dendrimer space concept for innovative nanomedicine: A futuristic vision for medicinal chemistry, Progress in Polymer Science, Volume 38, Issue 7, Pages 993-1008, ISSN 0079-6700.

[201] Eaton, M. A. W., Levy, L., Fontaine, O. M. A. (2015). Delivering nanomedicines to patients: A practical guide, Nanomedicine: Nanotechnology, Biology and Medicine, Volume 11, Issue 4, Pages 983-992, ISSN 1549-9634

[202] Lollo, G., Hervella, P., Calvo, P., Avilés, P., Guillén, M. J., Garcia-Fuentes, M., Alonso, M. J., Torres, D. (2015). Enhanced therapeutic efficacy of plitidepsin-loaded nanocapsules decorated with a new poly-aminoacid-PEG derivative, International Journal of Pharmaceutics, Volume 483, Issue 1, Pages 212-219, ISSN 03785173 .

[203] Thompson, N., Ahn, M., Chessari, G., Hearn, K., Johnson, C. N., Lewis, J., Ward, G., Williams, P., Woolford, A. (2012). 85 Characterization of a Potent XIAP and CIAP1 Dual Antagonist in Models of Melanoma and Leukemia, European Journal of Cancer, Volume 48, Page 27, ISSN 0959-8049.

[204] Graphical Abstracts, Journal of Fluorine Chemistry, Volume 174, 2015, Pages vii-xii, ISSN 0022-1139.

[205] Muntimadugu, E., Kommineni, N., Khan, W. (2017). Exploring the Potential of Nanotherapeutics in Targeting Tumor Microenvironment for Cancer Therapy, Pharmacological Research, ISSN 1043-6618.

[206] Foldvari, M., Bagonluri, M. (2008). Carbon nanotubes as functional excipients for nanomedicines: II. Drug delivery and biocompatibility issues, Nanomedicine: Nanotechnology, Biology and Medicine, Volume 4, Issue 3, Pages 183-200, ISSN 1549-9634.

[207] Graphical Abstracts, Journal of Fluorine Chemistry, Volume 171, 2015, Pages vii-xiii, ISSN 0022-1139.

[208] Riley, J.S., Johnston, P.G., Longley, D.B. (2012). 83 Investigation of Post-translational Modifications of c-FLIP, European Journal of Cancer, Volume 48, Page 27, ISSN 0959-8049, http://dx.doi.org/10.1016/S0959-8049(12)71881-6.

[209] Fernandes, E., Ferreira, J. A., Andreia, P., Luís, L., Barroso, S., Sarmento, B., Santos, L. L. (2015). New trends in guided nanotherapies for digestive cancers: A systematic review, Journal of Controlled Release, Volume 209, Pages 288-307, ISSN 0168-3659.

[210] Mehra, N. K., Palakurthi, S. (2016). Interactions between carbon nanotubes and bioactives: a drug delivery perspective, Drug Discovery Today, Volume 21, Issue 4, Pages 585-597, ISSN 13596446. 
[211] Mignani, S., Huber, S., Tomás, H., Rodrigues, J., Majoral, J. P (2016). Why and how have drug discovery strategies in pharma changed? What are the new mindsets?, Drug Discovery Today, Volume 21, Issue 2, Pages 239-249, ISSN 1359-6446.

[212] Naderkhani, E., Erber, A., Škalko-Basnet, N., Flaten, G. E (2014). Improved Permeability of Acyclovir: Optimization of Mucoadhesive Liposomes Using the Phospholipid Vesicle-Based Permeation Assay, Journal of Pharmaceutical Sciences, Volume 103, Issue 2, Pages 661-668, ISSN 0022-3549.

[213] Newton, D. (2013). Literature listing, World Patent Information, Volume 35, Issue 4, Pages 352-357, ISSN 0172-2190.

[214] Aoki, I., Yoneyama, M., Hirose, J., Minemoto, Y., Koyama, T., Kokuryo, D., Bakalova, R., Murayama, S., Saga, T., Aoshima, S., Ishizaka, Y., Kono, K. (2015). Thermoactivatable polymer-grafted liposomes for low-invasive image-guided chemotherapy, Translational Research, Volume 166, Issue 6, Pages 660-673.e1, ISSN 1931-5244.

[215] Ita, K.B. (2014). Transdermal drug delivery: progress and challenges, Journal of Drug Delivery Science and Technology, Volume 24, Issue 3, Pages 245-250, ISSN 1773-2247.

[216] Liu, J. R., Chen, G. F., Shih, H. N., Kuo, P. C. (2008). Enhanced antioxidant bioactivity of (Danshen) products prepared using nanotechnology, Phytomedicine, Volume 15, Issue 1, Pages $23-$ 30, ISSN 0944-7113.

[217] Mallapragada, S. K., Brenza, T. M., McMillan, J. M., Narasimhan, B., Sakaguchi, D. S., Sharma, A. D., Zbarska, S., Gendelman, H. E. (2015). Enabling nanomaterial, nanofabrication and cellular technologies for nanoneuromedicines, Nanomedicine: Nanotechnology, Biology and Medicine, Volume 11, Issue 3, Pages 715-729, ISSN 1549-9634.

[218] Peres, C., Matos, A. I., Conniot, J., Sainz, V., Zupančič, E., Silva, J. M., Graça, L., Gaspar, R. S., Préat, V., Florindo, H. F. (2017). Poly(lactic acid)-based particulate systems are promising tools for immune modulation, Acta Biomaterialia, Volume 48, Pages 41-57, ISSN 1742-7061.

[219] Ferreira, A. J., Cemlyn-Jones, J., Cordeiro, C. R. (2013). Nanoparticles, nanotechnology and pulmonary nanotoxicology, Revista Portuguesa de Pneumologia (English Edition), Volume 19, Issue 1, Pages 28-37, ISSN 2173-5115.

[220] Ferreira, A. J., Cemlyn-Jones, J., Cordeiro, C. R. (2013). Nanoparticles, nanotechnology and pulmonary nanotoxicology, Revista Portuguesa de Pneumologia, Volume 19, Issue 1, Pages 28-37, ISSN 0873-2159.

[221] Salerno, A., Pascual, C. D. (2015). Bio-based polymers, supercritical fluids and tissue engineering, Process Biochemistry, Volume 50, Issue 5, Pages 826-838, ISSN 1359-5113.

[222] Tyler, B., Gullotti, D., Mangraviti, A., Utsuki, T., Brem, H. (2016). Polylactic acid (PLA) controlled delivery carriers for biomedical applications, Advanced Drug Delivery Reviews, Volume 107, Pages 163-175, ISSN 0169-409X.

[223] Iannazzo, D., Pistone, A., Galvagno, S., Ferro, S., Luca, L. D., Monforte, A. M., Ros, T. D., Hadad, C., Prato, M., Pannecouque, C. (2015). Synthesis and anti-HIV activity of carboxylated and drug-conjugated multi-walled carbon nanotubes, Carbon, Volume 82, Pages 548-561, ISSN 0008-6223.

[224] Jemec, A., Djinović, P., Tišler, T., Pintar, A. (2012). Effects of four $\mathrm{CeO}$ nanocrystalline catalysts on early-life stages of zebrafish and crustacean , Journal of Hazardous Materials, Volume 219, Pages 213-220, ISSN 0304-3894.

[225] Chen, H.L., Tai, W.T., Shiau, C.W., Liu, C.Y., Lin, C.S., Cheng, A.L., Chen, P.J., Chen, K.F. (2012). 82 Sorafenib and Its Derivative SC-59 Induces Autophagy in Hepatocellular Carcinoma Through SHP-1 Dependent Inhibition of STAT3, European Journal of Cancer, Volume 48, Pages 26-27, ISSN 0959-8049.

[226] Lütscher, N., Hönes, S., Grubert, M., Scheulen, M.E., Hilger, R.A. (2012). 86 Antitumoral Activity of a New Class of Triazenes, European Journal of Cancer, Volume 48, Pages 27-28, ISSN 09598049.

[227] Park, C. W., Li, X., Vogt, F. G., Hayes, D., Zwischenberger, J. B., Park, E. S., Mansour, H. M. (2013). Advanced spray-dried design, physicochemical characterization, and aerosol dispersion performance of vancomycin and clarithromycin multifunctional controlled release particles for targeted respiratory delivery as dry powder inhalation aerosols, International Journal of Pharmaceutics, Volume 455, Issue 1, Pages 374-392, ISSN 0378-5173.

[228] Huang, H., Yuan, Q., Shah, J.S., Misra, R.D.K. (2011). A new family of folate-decorated and carbon nanotube-mediated drug delivery system: Synthesis and drug delivery response, Advanced Drug Delivery Reviews, Volume 63, Issue 14, Pages 1332-1339, ISSN 0169-409X, http://dx.doi.org/10.1016/j.addr.2011.04.001.
[229] Depan D., Shah, J., Misra, R.D.K. (2011). Controlled release of drug from folate-decorated and graphene mediated drug delivery system: Synthesis, loading efficiency, and drug release response, Materials Science and Engineering: C, Volume 31, Issue 7, Pages 1305-1312, ISSN 0928-4931.

[230] Guo, S., Huang, L. (2014). Nanoparticles containing insoluble drug for cancer therapy, Biotechnology Advances, Volume 32, Issue 4, Pages 778-788, ISSN 0734-9750, http://dx.doi.org/10.1016/j.biotechadv.2013.10.002.

[231] Duncan, R. (2011). Polymer therapeutics as nanomedicines: new perspectives, Current Opinion in Biotechnology, Volume 22 Issue 4, Pages 492-501, ISSN 0958-1669.

[232] Sidik, N. A. C.Yazid, M. N. A. W. M., Samion, S., Musa, M. N., Mamat, R. (2016). Latest development on computational approaches for nanofluid flow modeling: Navier-Stokes based multiphase models, International Communications in Heat and Mass Transfer, Volume 74, Pages 114-124, ISSN 0735-1933, http://dx.doi.org/10.1016/j.icheatmasstransfer.2016.03.007.

[233] Yuan, Q., Hein, S., Misra, R. D. K. (2010). New generation of chitosan-encapsulated $\mathrm{ZnO}$ quantum dots loaded with drug: Synthesis, characterization and in vitro drug delivery response, Acta Biomaterialia, Volume 6, Issue 7, Pages 2732-2739, ISSN 1742 7061, http://dx.doi.org/10.1016/j.actbio.2010.01.025.

[234] He, W., Liu, Y., Wamer, W. G., Yin, J. J. (2014). Electron spin resonance spectroscopy for the study of nanomaterial-mediated generation of reactive Oxygen species, Journal of Food and Drug Analysis, Volume 22, Issue 1, Pages 49-63, ISSN 1021-9498, http://dx.doi.org/10.1016/j.jfda.2014.01.004.

[235] An, J., Gou, Y., Yang, C., Hu, F., Wang, C. (2013). Synthesis of a biocompatible gelatin functionalized graphene nanosheets and its application for drug delivery, Materials Science and Engineering: C, Volume 33, Issue 5, Pages 2827-2837, ISSN 0928-4931, http://dx.doi.org/10.1016/j.msec.2013.03.008.

[236] Meenach, S. A., Anderson, K. W., Hilt, J. Z., McGarry, R. C., Mansour, H. M. (2013). Characterization and aerosol dispersion performance of advanced spray-dried chemotherapeutic PEGylated phospholipid particles for dry powder inhalation delivery in lung cancer, European Journal of Pharmaceutical Sciences, Volume 49, Issue 4, Pages 699-711, ISSN 0928-0987, http://dx.doi.org/10.1016/j.ejps.2013.05.012.

[237] England, R. M., Masiá, E., Giménez, V., Lucas, R., Vicent, M. J. (2012). Polyacetal-stilbene conjugates - the first examples of polymer therapeutics for the inhibition of HIF-1 in the treatment of solid tumours, Journal of Controlled Release, Volume 164, Issue 3 , Pages 314-322, $\quad$ ISSN $0168-3659$, http://dx.doi.org/10.1016/j.jconrel.2012.08.017.

[238] Pippa, N., Merkouraki, M., Pispas, S., Demetzos, C. (2013). DPPC:MPOx chimeric advanced Drug Delivery nano Systems (chiaDDnSs): Physicochemical and structural characterization, stability and drug release studies, International Journal of Pharmaceutics, Volume 450, Issue 1, Pages 1-10, ISSN 0378-5173, http://dx.doi.org/10.1016/j.ijpharm.2013.03.052.

[239] Boisseau, P., Loubaton, B. (2011). Nanomedicine, nanotechnology in medicine, Comptes Rendus Physique, Volume 12, Issue 7, Pages 620-636, ISSN 1631-0705, http://dx.doi.org/10.1016/j.crhy.2011.06.001.

[240] Petrichenko, O., Rucins, M., Vezane, A., Timofejeva, I., Sobolev, A., Cekavicus, B., Pajuste, K., Plotniece, M., Gosteva, M., Kozlovska, T., Plotniece, A. (2015). Studies of the physicochemical and structural properties of self-assembling cationic pyridine derivatives as gene delivery agents, Chemistry and Physics of Lipids, Volume 191, Pages 25-37, ISSN 0009-3084, http://dx.doi.org/10.1016/j.chemphyslip.2015.08.005.

[241] Rodríguez-Gascón, A., Del Pozo-Rodríguez, A., Isla, A., Solinís, M. A. (2015). Vaginal gene therapy, Advanced Drug Delivery Reviews, Volume 92, Pages 71-83, ISSN 0169-409X, http://dx.doi.org/10.1016/j.addr.2015.07.002.

[242] Frima, H. J., Gabellieri, C., Nilsson, M. I. (2012). Drug delivery research in the European Union's Seventh Framework Programme for Research, Journal of Controlled Release, Volume 161, Issue 2, Pages 409-415, ISSN 0168-3659, http://dx.doi.org/10.1016/j.jconrel.2012.01.044.

[243] Yallapu, M. M., Chauhan, N., Othman, S. F., KhalilzadSharghi, V., Ebeling, M. C., Khan, S., Jaggi, M., Chauhan, S. C. (2015). Implications of protein corona on physico-chemical and biological properties of magnetic nanoparticles, Biomaterials, Volume 46, Pages 1-12, ISSN 0142-9612, http://dx.doi.org/10.1016/j.biomaterials.2014.12.045.

[244] Duan, J., Mansour, H. M., Zhang, Y., Deng, X., Chen, Y., Wang, J., Pan, Y., Zhao, J. (2012). Reversion of multidrug re- 
sistance by co-encapsulation of doxorubicin and curcumin in chitosan/poly(butyl cyanoacrylate) nanoparticles, International Journal of Pharmaceutics, Volume 426, Issue 1, Pages 193-201, ISSN 0378-5173, http://dx.doi.org/10.1016/j.ijpharm.2012.01.020.

[245] Perez, R. A., Kim, H. W. (2015). Core-shell designed scaffolds for drug delivery and tissue engineering, Acta Biomaterialia, Volume 21, Pages 2-19, ISSN 1742-7061, http://dx.doi.org/10.1016/j.actbio.2015.03.013.

[246] Costantino, L., Boraschi, D. (2012). Is there a clinical future for polymeric nanoparticles as brain-targeting drug delivery agents? Drug Discovery Today, Volume 17, Issue 7, Pages 367-378, ISSN 1359-6446, https://doi.org/10.1016/j.drudis.2011.10.028.

[247] Wei, C., Lyubchenko, Y. L., Ghandehari, H., Hanes, J., Stebe, K. J., Mao, H. Q., Haynie, D. T., Tomalia, D. A., Foldvari, M., Monteiro-Riviere, N., Simeonova, P., Nie, S., Mori, H., Gilbert, S P., Needham, D. (2006). New technology and clinical applications of nanomedicine: Highlights of the second annual meeting of the American Academy of Nanomedicine (Part I), Nanomedicine: Nanotechnology, Biology and Medicine, Volume 2, Issue 4, Pages 253-263, ISSN

$1549-9634$ http://dx.doi.org/10.1016/j.nano.2006.11.001.

[248] Murday, J. S., Siegel, R. W., Stein, J., Wright, J. F. (2009) Translational nanomedicine: status assessment and opportunities, Nanomedicine: Nanotechnology, Biology and Medicine, Volume 5, Issue 3, Pages 251-273, ISSN 1549-9634, http://dx.doi.org/10.1016/j.nano.2009.06.001.

[249] Dixit, N., Vaibhav, K., Pandey, R. S., Jain, U. K., Katare, O. P., Katyal, A., Madan, J. (2015). Improved cisplatin delivery in cervical cancer cells by utilizing folate-grafted non-aggregated gelatin nanoparticles, Biomedicine \& Pharmacotherapy, Volume 69, Pages 1-10, ISSN 0753-3322, http://dx.doi.org/10.1016/j.biopha.2014.10.016

[250] Nair, H. B., Sung, B., Yadav, V. R., Kannappan, R., Chaturvedi, M. M., Aggarwal, B. B. (2010). Delivery of antiinflammatory nutraceuticals by nanoparticles for the prevention and treatment of cancer, Biochemical Pharmacology, Volume 80, Issue 12, Pages 1833-1843, ISSN

0006-2952 http://dx.doi.org/10.1016/j.bcp.2010.07.021.

[251] Bawa, R., Bawa, S.R., Maebius, S. B., Flynn, T., Wei, C. (2005). Protecting new ideas and inventions in nanomedicine with patents, Nanomedicine: Nanotechnology, Biology and Medicine, Volume 1, Issue 2, Pages 150-158, ISSN 1549-9634, http://dx.doi.org/10.1016/j.nano.2005.03.009.

[252] Farkhani, S. M., Valizadeh, A., Karami, H., Mohammadi, S. Sohrabi, N., Badrzadeh, F. (2014). Cell penetrating peptides: Efficient vectors for delivery of nanoparticles, nanocarriers, therapeutic and diagnostic molecules, Peptides, Volume 57, Pages 78-94, ISSN 0196-9781, http://dx.doi.org/10.1016/j.peptides.2014.04.015.

[253] Graphical Abstracts, Journal of Fluorine Chemistry, Volume 168, 2014, Pages V-xv, ISSN 0022-1139, http://dx.doi.org/10.1016/S0022-1139(14)00353-4.

[254] Lal, R., Arnsdorf, M. F. (2010). Multidimensional atomic force microscopy for drug discovery: A versatile tool for defining targets, designing therapeutics and monitoring their efficacy, Life Sciences, Volume 86, Issue 15, Pages 545-562, ISSN 0024-3205, http://dx.doi.org/10.1016/j.lfs.2009.02.030.

[255] Hacklin, F., Marxt, C., Fahrni, F. (2009). Coevolutionary cycles of convergence: An extrapolation from the ICT industry, Technological Forecasting and Social Change, Volume 76, Issue 6, Pages 723-736, ISSN $0040-1625$ https://doi.org/10.1016/j.techfore.2009.03.003.

[256] Gabizon, A. A., Patil, Y., La-Beck, N. M. (2016). New insights and evolving role of pegylated liposomal doxorubicin in cancer therapy, Drug Resistance Updates, Volume 29, Pages 90-106, ISSN 1368-7646, http://dx.doi.org/10.1016/j.drup.2016.10.003.

[257] Zhang, J., Ma, P. X. (2013). Cyclodextrin-based supramolecular systems for drug delivery: Recent progress and future perspective, Advanced Drug Delivery Reviews, Volume 65, Issue 9, Pages 1215-1233, ISSN

0169-409X, http://dx.doi.org/10.1016/j.addr.2013.05.001

[258] Vanić, Ž. Škalko-Basnet, N. (2014). Mucosal nanosystems for improved topical drug delivery: vaginal route of administration, Journal of Drug Delivery Science and Technology, Volume 24, Issue 5, Pages 435-444, ISSN 1773-2247, http://dx.doi.org/10.1016/S1773-2247(14)50085-8

[259] Ellis-Behnke, R. (2007). Nano Neurology and the Four P's of Central Nervous System Regeneration: Preserve, Permit, Promote, Plasticity, Medical Clinics of North America, Volume 91, Issue 5 , Pages 937-962, ISSN 0025-7125, http://dx.doi.org/10.1016/j.mcna.2007.04.005.
[260] Srivalli, K. M. R., Mishra, B. (2016). Drug nanocrystals: A way toward scale-up, Saudi Pharmaceutical Journal, Volume 24, Issue 4, Pages 386-404, ISSN 1319-0164, http://dx.doi.org/10.1016/j.jsps.2014.04.007.

[261] Collnot, E. M., Ali, H., Lehr, C. M. (2012). Nano- and microparticulate drug carriers for targeting of the inflamed intestinal mucosa, Journal of Controlled Release, Volume 161, Issue 2, Pages 235-246, ISSN http://dx.doi.org/10.1016/j.jconrel.2012.01.028.

[262] Rychak, J. J., Lindner, J. R., Ley, K., Klibanov, A. L. (2006) Deformable gas-filled microbubbles targeted to P-selectin, Journal of Controlled Release, Volume 114, Issue 3, Pages 288-299, ISSN 0168-3659, and http://dx.doi.org/10.1016/j.jconrel.2006.06.008.

[263] Watala, C., Karolczak, K., Kassassir, H., Talar, M., Przygodzki, T., Maczynska, K., Labieniec-Watala, M. (2016). How do the full-generation poly (amido) amine (PAMAM) dendrimers activate blood platelets? Activation of circulating platelets and formation of fibrinogen aggregates in the presence of polycations, International Journal of Pharmaceutics, Volume 503, Issue 1, Pages 247-261, ISSN

http://dx.doi.org/10.1016/j.ijpharm.2015.08.073.

[264] Palombo, M.S., Singh, Y., Sinko, P.J. (2009). Prodrug and conjugate drug delivery strategies for improving HIV/AIDS therapy, Journal of Drug Delivery Science and Technology, Volume 19, Issue 1, Pages 3-14, ISSN 1773-2247, http://dx.doi.org/10.1016/S1773-2247(09)50001-9.

[265] Table of Contents, Nanomedicine: Nanotechnology, Biology and Medicine, Volume 7, Issue 4, 2011, Pages A4-A5, ISSN 15499634, http://dx.doi.org/10.1016/S1549-9634(11)00192-4.

[266] Kuzmov, A., Minko, T. (2015). Nanotechnology approaches for inhalation treatment of lung diseases, Journal of Controlled Release, Volume 219, Pages 500-518, and ISSN 0168-3659, http://dx.doi.org/10.1016/j.jconrel.2015.07.024

[267] Diebold, Y., Calonge, M. (2010). Applications of nanoparticles in ophthalmology, Progress in Retinal and Eye Research, Volume 29, Issue 6, Pages 596-609, ISSN 1350-9462, http://dx.doi.org/10.1016/j.preteyeres.2010.08.002.

[268] Bal, R., Türk, G., Tuzcu, M., Yilmaz, O., Ozercan, I., Kuloglu, T., Gür, S., Nedzvetsky, V. S., Tykhomyrov, A. A., Andrievsky, G. V., Baydas, G., Naziroglu, M. (2011). Protective effects of nanostructures of hydrated $\mathrm{C}$ fullerene on reproductive function in streptozotocin-diabetic male rats, Toxicology, Volume 282, Issue 3 , Pages 69-81, ISSN 0300-483X http://dx.doi.org/10.1016/j.tox.2010.12.003

[269] Bharali, D. J., Mousa, S. A. (2010). Emerging nanomedicines for early cancer detection and improved treatment: Current perspective and future promise, Pharmacology \& Therapeutics, Volume 128, Issue 2, Pages 324-335, ISSN 0163-7258, http://dx.doi.org/10.1016/j.pharmthera.2010.07.007.

[270] Ray, S., Chandra, H., Srivastava, S. (2010). Nanotechniques in proteomics: Status, promises and challenges, Biosensors and Bioelectronics, Volume 25, Issue 11, Pages 2389-2401, ISSN 0956 5663, http://dx.doi.org/10.1016/j.bios.2010.04.010.

[271] Mishra, B., Patel, B. B., Tiwari, S. (2010). Colloidal nanocarriers: a review on formulation technology, types and applications toward targeted drug delivery, Nanomedicine: Nanotechnology, Biology and Medicine, Volume 6, Issue 1, Pages 9-24, ISSN 15499634, http://dx.doi.org/10.1016/j.nano.2009.04.008

[272] Contents, Nanomedicine: Nanotechnology, Biology and Medicine, Volume 4, Issue 4, 2008, Pages A3-A4, ISSN 1549-9634, http://dx.doi.org/10.1016/S1549-9634(08)00178-0.

[273] Torchilin, V. (2009). Multifunctional and stimuli-sensitive pharmaceutical nanocarriers, European Journal of Pharmaceutics and Biopharmaceutics, Volume 71, Issue 3, Pages 431-444, ISSN 0939-6411, http://dx.doi.org/10.1016/j.ejpb.2008.09.026.

[274] Cupaioli, F. A., Zucca, F. A., Boraschi, D., Zecca, L. (2014). Engineered nanoparticles. How brain friendly is this new guest? Progress in Neurobiology, Volume 119, Pages 20-38, ISSN 03010082, http://dx.doi.org/10.1016/j.pneurobio.2014.05.002.

[275] Sosnik, A., Carcaboso, A. M. (2014). Nanomedicines in the future of pediatric therapy, Advanced Drug Delivery Reviews, Volume 73, Pages 140-161, ISSN 0169-409X, http://dx.doi.org/10.1016/j.addr.2014.05.004

[276] Table of Contents, Nanomedicine: Nanotechnology, Biology and Medicine, Volume 10, Issue 1, 2014, Pages A4-A7, ISSN 1549-9634, http://dx.doi.org/10.1016/S1549-9634(13)00599-6.

[277] Guan, J., Zhao, Q. (2013). The impact of university-industry collaboration networks on innovation in nanobiopharmaceuticals, Technological Forecasting and Social Change, Volume 80, Issue 7, 
Pages 1271-1286, ISSN 0040-1625, http://dx.doi.org/10.1016/j.techfore.2012.11.013.

[278] Toit, L. C. D., Govender, T., Carmichael, T., Kumar, P., Choonara, Y. E., Pillay, V. (2013). Design of an Anti-Inflammatory Composite Nanosystem and Evaluation of Its Potential for Ocular Drug Delivery, Journal of Pharmaceutical Sciences, Volume 102, Issue $\quad 8, \quad$ Pages 2780-2805, ISSN 0022-3549, http://dx.doi.org/10.1002/jps.23650.

[279] Emerging Fields, Free Radical Biology and Medicine, Volume 43, 2007, Pages S67-S74, ISSN 0891-5849, http://dx.doi.org/10.1016/j.freeradbiomed.2007.10.018.

[280] Zhang, X. Q., Xu, X., Bertrand, N., Pridgen, E., Swami, A., Farokhzad, O. C. (2012). Interactions of nanomaterials and biological systems: Implications to personalized nanomedicine, Advanced Drug Delivery Reviews, Volume 64, Issue 13, Pages 1363-1384, ISSN 0169-409X, http://dx.doi.org/10.1016/j.addr.2012.08.005.

[281] Muthaiyan, A., Limayem, A., Ricke, S. C. (2011). Antimicrobial strategies for limiting bacterial contaminants in fuel bioethanol fermentations, Progress in Energy and Combustion Science, Volume 37, Issue 3, Pages 351-370, ISSN 0360-1285, http://dx.doi.org/10.1016/j.pecs.2010.06.005.

[282] Scientific Programme - Details, European Journal of Cancer Supplements, Volume 8, Issue 7, 2010, Pages xxiv-lxvi, ISSN 1359-6349, http://dx.doi.org/10.1016/S1359-6349(10)71697-9.

[283] Subject Index, European Journal of Cancer Supplements, Volume 8, Issue 7, 2010, Pages 233-243, ISSN 1359-6349, http://dx.doi.org/10.1016/S1359-6349(10)72373-9.

[284] Duncan, R. (2009). Development of HPMA copolymeranticancer conjugates: Clinical experience and lessons learnt, Advanced Drug Delivery Reviews, Volume 61, Issue 13, Pages 11311148, and ISSN $0169-409$ X, http://dx.doi.org/10.1016/j.addr.2009.05.007.

[285] Palao-Suay, R., Gómez-Mascaraque, L.G., Aguilar, M.R., Vázquez-Lasa, B., Román, J. S. (2016). Self-assembling polymer systems for advanced treatment of cancer and inflammation, Progress in Polymer Science, Volume 53, Pages 207-248, ISSN 00796700, http://dx.doi.org/10.1016/j.progpolymsci.2015.07.005.

[286] Morrow, K. J., Bawa, R., Wei, C. (2007). Recent Advances in Basic and Clinical Nanomedicine, Medical Clinics of North America, Volume 91, Issue 5, Pages 805-843, ISSN 0025-7125, http://dx.doi.org/10.1016/j.mcna.2007.05.009.

[287] Tissue/Cell Targets and Reactions, Free Radical Biology and Medicine, Volume 41, 2006, Pages S144-S154, ISSN 0891-5849, http://dx.doi.org/10.1016/j.freeradbiomed.2006.10.015.

[288] Inflammation, Free Radical Biology and Medicine, Volume 41, 2006, Pages S68-S78, ISSN 0891-5849, http://dx.doi.org/10.1016/j.freeradbiomed.2006.10.008.

[289] Punetha, V. D., Rana, S., Yoo, H. J., Chaurasia, A., McLeskey, J. T., Ramasamy, M. S., Sahoo, N. G., Cho, J. W. (2017). Functionalization of carbon nanomaterials for advanced polymer nanocomposites: A comparison study between CNT and graphene, Progress in Polymer Science, Volume 67, Pages 1-47, ISSN 0079-6700, http://dx.doi.org/10.1016/j.progpolymsci.2016.12.010.

[290] Antioxidants, Nutrition \& Health, Free Radical Biology and Medicine, Volume 41, 2006, Pages S18-S31, ISSN 0891-5849, http://dx.doi.org/10.1016/j.freeradbiomed.2006.10.002.

[291] Scientific Programme - Proffered Papers, European Journal of Cancer, Volume 49, 2013, Pages S97-S153, ISSN 0959-8049, http://dx.doi.org/10.1016/S0959-8049(13)70060-1.

[292] Subject Index, European Journal of Cancer, Volume 49, 2013, Pages S975-S1028, ISSN 0959-8049, http://dx.doi.org/10.1016/S0959-8049(13)70067-4.

[293] Goldschmidt Abstracts $2010-\mathrm{H}$, Geochimica et Cosmochimica Acta, Volume 74, Issue 12, 2010, Pages A369-A440, ISSN 0016-7037, http://dx.doi.org/10.1016/.j.gca.2010.04.033.

[294] Manickam, S. (2017). Editorial Note, Ultrasonics Sonochemistry, Volume 35, Pages 529-530, ISSN 1350-4177, http://dx.doi.org/10.1016/j.ultsonch.2016.06.028.

[295] Osorio, J. G., Muzzio, F. J. (2015). Evaluation of resonant acoustic mixing performance, Powder Technology, Volume 278, Pages 46-56, ISSN 0032-5910, http://dx.doi.org/10.1016/j.powtec.2015.02.033.

[296] Karami, Z., Hamidi, M. (2016). Cubosomes: remarkable drug delivery potential, Drug Discovery Today, Volume 21, Issue 5, Pages 789-801, ISSN 1359-6446, http://dx.doi.org/10.1016/j.drudis.2016.01.004

[297] Park, J., Nam, H., Ahn, S. Y., Pak, Y. K., Pak, J. J. (2013). A reservoir-type oxygen sensor with $2 \times 3$ array for measuring cellular respiration levels, Sensors and Actuators B: Chemical, Volume
176, Pages 913-920, ISSN 0925-4005, http://dx.doi.org/10.1016/j.snb.2012.09.037.

[298] Heidari, A. (2017). Investigation of Anti-Cancer Nano Drugs Effects' Trend on Human Pancreas Cancer Cells and Tissues Prevention, Diagnosis and Treatment Process under Synchrotron and X-Ray Radiations with the Passage of Time Using Mathematica, Current Trends Anal Bioanal Chem, 1 (1): 36-41.

[299] Heidari, A. (2017). Pros and Cons Controversy on Molecular Imaging and Dynamics of Double-Standard DNA/RNA of Human Preserving Stem Cells-Binding Nano Molecules with Androgens/Anabolic Steroids (AAS) or Testosterone Derivatives through Tracking of Helium-4 Nucleus (Alpha Particle) Using Synchrotron Radiation, Arch Biotechnol Biomed. One (1): 067-0100.

[300] Heidari, A. (2017). Visualizing Metabolic Changes in Probing Human Cancer Cells and Tissues Metabolism Using Vivo ${ }^{1} \mathrm{H}$ or Proton NMR, ${ }^{13} \mathrm{C}$ NMR, ${ }^{15} \mathrm{~N}$ NMR and ${ }^{31} \mathrm{P}$ NMR Spectroscopy and Self-Organizing Maps under Synchrotron Radiation, SOJ Mater Sci Eng 5 (2): 1-6.

[301] Heidari, (2017). A. Cavity Ring-Down Spectroscopy (CRDS), Circular Dichroism Spectroscopy, Cold Vapour Atomic Fluorescence Spectroscopy and Correlation Spectroscopy Comparative Study on Malignant and Benign Human Cancer Cells and Tissues with the Passage of Time under Synchrotron Radiation, Enliven: Challenges Cancer Detect Ther 4 (2): e001.

[302] Heidari, A. (2017). Laser Spectroscopy, Laser-Induced Breakdown Spectroscopy and Laser-Induced Plasma Spectroscopy Comparative Study on Malignant and Benign Human Cancer Cells and Tissues with the Passage of Time under Synchrotron Radiation, Int J Hepatol Gastroenterol, 3 (4): 079-084.

[303] Heidari, A. (2017). Time-Resolved Spectroscopy and TimeStretch Spectroscopy Comparative Study on Malignant and Benign Human Cancer Cells and Tissues with the Passage of Time under Synchrotron Radiation, Enliven: Pharmacovigilance and Drug Safety 4 (2): e001.

[304] Heidari, A. (2017). Overview of the Role of Vitamins in Reducing Negative Effect of Decapeptyl (Triptorelin Acetate or Pamoate Salts) on Prostate Cancer Cells and Tissues in Prostate Cancer Treatment Process through Transformation of Malignant Prostate Tumors into Benign Prostate Tumors under Synchrotron Radiation, Open J Anal Bioanal Chem 1 (1): 021-026.

[305] Heidari, A. (2017). Electron Phenomenological Spectroscopy, Electron Paramagnetic Resonance (EPR) Spectroscopy and Electron Spin Resonance (ESR) Spectroscopy Comparative Study on Malignant and Benign Human Cancer Cells and Tissues with the Passage of Time under Synchrotron Radiation, Austin J Anal Pharm Chem. 4 (3): 1091.

[306] Heidari, A. (2017). Therapeutic Nanomedicine Different HighResolution Experimental Images and Computational Simulations for Human Brain Cancer Cells and Tissues Using Nanocarriers Deliver DNA/RNA to Brain Tumors under Synchrotron Radiation with the Passage of Time Using Mathematica and MATLAB, Madridge J Nano Tech. Sci. 2 (2): 77-83.

[307] Heidari, A. (2017). A Consensus and Prospective Study on Restoring Cadmium Oxide (CdO) Nanoparticles Sensitivity in Recurrent Ovarian Cancer by Extending the Cadmium Oxide (CdO) Nanoparticles-Free Interval Using Synchrotron Radiation Therapy as Antibody-Drug Conjugate for the Treatment of Limited-Stage Small Cell Diverse Epithelial Cancers, Cancer Clin Res Rep, 1: 2, e001.

[308] Heidari, A. (2017). A Novel and Modern Experimental Imaging and Spectroscopy Comparative Study on Malignant and Benign Human Cancer Cells and Tissues with the Passage of Time under White Synchrotron Radiation, Cancer Sci Res Open Access 4 (2): $1-8$.

[309] Heidari, A. (2017). Different High-Resolution Simulations of Medical, Medicinal, Clinical, Pharmaceutical and Therapeutics Oncology of Human Breast Cancer Translational Nano Drugs Delivery Treatment Process under Synchrotron and X-Ray Radiations, J Oral Cancer Res 1 (1): 12-17.

[310] Heidari, A. (2017). Vibrational Decihertz (dHz), Centihertz $(\mathrm{cHz})$, Millihertz $(\mathrm{mHz})$, Microhertz $(\mu \mathrm{Hz})$, Nanohertz $(\mathrm{nHz})$, Picohertz (pHz), Femtohertz (fHz), Attohertz (aHz), Zeptohertz (zHz) and Yoctohertz $(\mathrm{yHz})$ Imaging and Spectroscopy Comparative Study on Malignant and Benign Human Cancer Cells and Tissues under Synchrotron Radiation, International Journal of Biomedicine, 7 (4), 335-340. https://doi.org/10.21103/Article7(4)_IA1.

[311] Heidari, A. (2017). Force Spectroscopy and Fluorescence Spectroscopy Comparative Study on Malignant and Benign Human Cancer Cells and Tissues with the Passage of Time under Synchrotron Radiation, EC Cancer, 2 (5), 239-246. 
[312] Heidari, A. (2017). Photoacoustic Spectroscopy, Photoemission Spectroscopy and Photothermal Spectroscopy Comparative Study on Malignant and Benign Human Cancer Cells and Tissues with the Passage of Time under Synchrotron Radiation, BAOJ Cancer Res Ther, 3: 3, 045-052.

[313] Heidari, A. (2017). J-Spectroscopy, Exchange Spectroscopy (EXSY), Nucle 7 ar Overhauser Effect Spectroscopy (NOESY) and Total Correlation Spectroscopy (TOCSY) Comparative Study on Malignant and Benign Human Cancer Cells and Tissues under Synchrotron Radiation, EMS Eng Sci J, 1 (2): 006-013.

[314] Heidari, A. (2017). Neutron Spin Echo Spectroscopy and Spin Noise Spectroscopy Comparative Study on Malignant and Benign Human Cancer Cells and Tissues with the Passage of Time under Synchrotron Radiation, Int J Biopharm Sci, 1: 103-107.

[315] Heidari, A. (2017). Vibrational Decahertz (daHz), Hectohertz $(\mathrm{hHz})$, Kilohertz (kHz), Megahertz (MHz), Gigahertz (GHz), Terahertz $(\mathrm{THz})$, Petahertz $(\mathrm{PHz})$, Exahertz $(\mathrm{EHz})$, Zettahertz $(\mathrm{ZHz})$ and Yottahertz (YHz) Imaging and Spectroscopy Comparative Study on Malignant and Benign Human Cancer Cells and Tissues under Synchrotron Radiation, Madridge J Anal Sci Instrum, 2 (1): 41-46.

[316] Heidari, A. (2018). Two-Dimensional Infrared Correlation Spectroscopy, Linear Two-Dimensional Infrared Spectroscopy and Non-Linear Two-Dimensional Infrared Spectroscopy Comparative Study on Malignant and Benign Human Cancer Cells and Tissues under Synchrotron Radiation with the Passage of Time, J Mater Sci Nanotechnol 6 (1): 101.

[317] Heidari, A. (2018). Infrared Photo Dissociation Spectroscopy and Infrared Correlation Table Spectroscopy Comparative Study on Malignant and Benign Human Cancer Cells and Tissues under Synchrotron Radiation with the Passage of Time, Austin Pharmacol Pharm, 3 (1): 1011.

[318] Heidari, A. (2018). Fourier Transform Infrared (FTIR) Spectroscopy, Near-Infrared Spectroscopy (NIRS) and Mid-Infrared Spectroscopy (MIRS) Comparative Study on Malignant and Benign Human Cancer Cells and Tissues under Synchrotron Radiation with the Passage of Time, Int J Nanotechnol Nanomed, 3 (1).

[319] Heidari, A. (2017). Novel and Transcendental Prevention, Diagnosis and Treatment Strategies for Investigation of Interaction among Human Blood Cancer Cells, Tissues, Tumors and Metastases with Synchrotron Radiation under Anti-Cancer Nano Drugs Delivery Efficacy Using MATLAB Modeling and Simulation, Madridge J Nov Drug Res, 1 (1): 18-24.

[320] Heidari, A. (2018). Comparative Study on Malignant and Benign Human Cancer Cells and Tissues with the Passage of Time under Synchrotron Radiation, Open Access J Trans Med Res, 2 (1), 00026. https://doi.org/10.15406/oajtmr.2018.02.00026.

[321] Gobato, M. R. R., Gobato, R., Heidari, A. (2018). Planting of Jaboticaba Trees for Landscape Repair of Degraded Area, Landscape Architecture and Regional Planning, Vol. 3, No. 1, 2018, Pages 1-9.

[322] Heidari, A. (2018). Fluorescence Spectroscopy, Phosphorescence Spectroscopy and Luminescence Spectroscopy Comparative Study on Malignant and Benign Human Cancer Cells and Tissues under Synchrotron Radiation with the Passage of Time, SM J Clin. Med. Imaging, 4 (1): 1018.

[323] Heidari, A. (2018). Nuclear Inelastic Scattering Spectroscopy (NISS) and Nuclear Inelastic Absorption Spectroscopy (NIAS) Comparative Study on Malignant and Benign Human Cancer Cells and Tissues under Synchrotron Radiation, Int J Pharm Sci, 2 (1): 114.

[324] Heidari, A. (2018). X-Ray Diffraction (XRD), Powder X-Ray Diffraction (PXRD) and Energy-Dispersive X-Ray Diffraction (EDXRD) Comparative Study on Malignant and Benign Human Cancer Cells and Tissues under Synchrotron Radiation, J Oncol Res; [2] (1): 1-14.

[325] Heidari, A. (2018). Correlation Two-Dimensional Nuclear Magnetic Reso $\neg$ nance (NMR) (2D-NMR) (COSY) Imaging and Spectrosco $\neg$ py Comparative Study on Malignant and Benign Human Cancer Cells and Tissues under Synchrotron Radiation, EMS Can Sci, 1-1-001.

[326] Heidari, A. (2018). Thermal Spectroscopy, Photothermal Spectroscopy, Thermal Microspectroscopy, Photothermal Microspectroscopy, Thermal Macrospectroscopy and Photothermal Macrospectroscopy Comparative Study on Malignant and Benign Human Cancer Cells and Tissues with the Passage of Time under Synchrotron Radiation, SM J Biometrics Biostat, 3 (1): 1024.

[327] Heidari, A. (2018). A Modern and Comprehensive Experimental Biospectroscopic Comparative Study on Human Common
Cancers' Cells, Tissues and Tumors before and after Synchrotron Radiation Therapy, Open Acc J Oncol Med. 1 (1).

[328] Heidari, A. (2018). Heteronuclear Correlation Experiments such as Heteronuclear Single-Quantum Correlation Spectroscopy (HSQC), Heteronuclear Multiple-Quantum Correlation Spectroscopy (HMQC) and Heteronuclear Multiple-Bond Correlation Spectroscopy (HMBC) Comparative Study on Malignant and Benign Human Endocrinology and Thyroid Cancer Cells and Tissues under Synchrotron Radiation, J Endocrinol Thyroid Res, 3 (1): 555603.

[329] Heidari, A. (2018). Nuclear Resonance Vibrational Spectroscopy (NRVS), Nuclear Inelastic Scattering Spectroscopy (NISS), Nuclear Inelastic Absorption Spectroscopy (NIAS) and Nuclear Resonant Inelastic X-Ray Scattering Spectroscopy (NRIXSS) Comparative Study on Malignant and Benign Human Cancer Cells and Tissues under Synchrotron Radiation, Int J Bioorg Chem Mol Biol. 6 (1e): $1-5$.

[330] Heidari, A. (2018). A Novel and Modern Experimental Approach to Vibrational Circular Dichroism Spectroscopy and Video Spectroscopy Comparative Study on Malignant and Benign Human Cancer Cells and Tissues with the Passage of Time under White and Monochromatic Synchrotron Radiation, Glob J Endocrinol Metab. 1 (3). GJEM. 000514-000519.

[331] Heidari, A. (2018). Pros and Cons Controversy on Heteronuclear Correlation Experiments such as Heteronuclear SingleQuantum Correlation Spectroscopy (HSQC), Heteronuclear Multiple-Quantum Correlation Spectroscopy (HMQC) and Heteronuclear Multiple-Bond Correlation Spectroscopy (HMBC) Comparative Study on Malignant and Benign Human Cancer Cells and Tissues under Synchrotron Radiation, EMS Pharma J. 1 (1): 002.

[332] Heidari, A. (2018). Saturated Spectroscopy and Unsaturated Spectroscopy Comparative Study on Malignant and Benign Human Cancer Cells and Tissues with the Passage of Time under Synchrotron Radiation, Imaging J Clin Medical Sci 5 (1): 001-007.

[333] Heidari, A. (2018). A Modern Comparative and Comprehensive Experimental Biospectroscopic Study on Different Types of Infrared Spectroscopy of Malignant and Benign Human Cancer Cells and Tissues with the Passage of Time under Synchrotron Radiation, J Analyt Molecul Tech. 3 (1): 8.

[334] Heidari, A. (2018). Investigation of Cancer Types Using Synchrotron Technology for Proton Beam Therapy: An Experimental Biospectroscopic Comparative Study, European Modern Studies Journal, Vol. 2, No. 1, 13-29, and 2018. With the Passage of Time under Synchrotron Radiation, Imaging J Clin Medical Sci. 5 (1): 001-007.

[335] Heidari, A. (2018). Small-Angle Neutron Scattering (SANS) and Wide-Angle X-Ray Diffraction (WAXD) Comparative Study on Malignant and Benign Human Cancer Cells and Tissues under Synchrotron Radiation, Int J Bioorg Chem Mol Biol. 6 (2e): 1-6.

[336] Heidari, A. (2018). Investigation of Bladder Cancer, Breast Cancer, Colorectal Cancer, Endometrial Cancer, Kidney Cancer, Leukemia, Liver, Lung Cancer, Melanoma, Non-Hodgkin Lymphoma, Pancreatic Cancer, Prostate Cancer, Thyroid Cancer and Non-Melanoma Skin Cancer Using Synchrotron Technology for Proton Beam Therapy: An Experimental Biospectroscopic Comparative Study, Ther Res Skin Dis 1 (1).

[337] Heidari, A. (2018). Attenuated Total Reflectance Fourier Transform Infrared (ATR-FTIR) Spectroscopy, Micro-Attenuated Total Reflectance Fourier Transform Infrared (Micro-ATR-FTIR) Spectroscopy and Macro-Attenuated Total Reflectance Fourier Transform Infrared (Macro-ATR-FTIR) Spectroscopy Comparative Study on Malignant and Benign Human Cancer Cells and Tissues under Synchrotron Radiation with the Passage of Time, International Journal of Chemistry Papers, 2 (1): 1-12.

[338] Heidari, A. (2018). Mössbauer Spectroscopy, Mössbauer Emission Spectroscopy and ${ }^{57} \mathrm{Fe}$ Mössbauer Spectroscopy Comparative Study on Malignant and Benign Human Cancer Cells and Tissues under Synchrotron Radiation, Acta Scientific Cancer Biology 2.3: 17-20.

[339] Heidari, A. (2018). Comparative Study on Malignant and Benign Human Cancer Cells and Tissues under Synchrotron Radiation with the Passage of Time, Organic \& Medicinal Chem IJ. [6] (1): 555676.

[340] Heidari, A. (2018). Correlation Spectroscopy, Exclusive Correlation Spectroscopy and Total Correlation Spectroscopy Comparative Study on Malignant and Benign Human AIDS-Related Cancers Cells and Tissues with the Passage of Time under Synchrotron Radiation, Int J Bioanal Biomed. Two (1): 001-007.

[341] Heidari, A. (2018). Biomedical Instrumentation and Applications of Biospectroscopic Methods and Techniques in Malignant and Benign Human Cancer Cells and Tissues Studies under Syn- 
chrotron Radiation and Anti-Cancer Nano Drugs Delivery, Am J Nanotechnol Nanomed. One (1): 001-009.

[342] Heidari, A. (2018). Vivo ${ }^{1} \mathrm{H}$ or Proton NMR, ${ }^{13} \mathrm{C}$ NMR, ${ }^{15} \mathrm{~N}$ NMR and ${ }^{31}$ P NMR Spectroscopy Comparative Study on Malignant and Benign Human Cancer Cells and Tissues under Synchrotron Radiation, Ann Biomet Biostat. One (1): 1001.

[343] Heidari, A. (2018). Grazing-Incidence Small-Angle Neutron Scattering (GISANS) and Grazing-Incidence X-Ray Diffraction (GIXD) Comparative Study on Malignant and Benign Human Cancer Cells, Tissues and Tumors under Synchrotron Radiation, Ann Cardiovasc Surg. 1 (2): 1006.

[344] Heidari, A. (2018). Adsorption Isotherms and Kinetics of Multi-Walled Carbon Nanotubes (MWCNTs), Boron Nitride Nanotubes (BNNTs), Amorphous Boron Nitride Nanotubes (a-BNNTs) and Hexagonal Boron Nitride Nanotubes (h-BNNTs) for Eliminating Carcinoma, Sarcoma, Lymphoma, Leukemia, Germ Cell Tumor and Blastoma Cancer Cells and Tissues, Clin Med Rev Case Rep 5: 201.

[345] Heidari, A. (2018). Correlation Spectroscopy (COSY), Exclusive Correlation Spectroscopy (ECOSY), Total Correlation Spectroscopy (TOCSY), Incredible Natural-Abundance DoubleQuantum Transfer Experiment (INADEQUATE), Heteronuclear Single-Quantum Correlation Spectroscopy (HSQC), Heteronuclear Multiple-Bond Correlation Spectroscopy (HMBC), Nuclear Overhauser Effect Spectroscopy (NOESY) and Rotating Frame Nuclear Overhauser Effect Spectroscopy (ROESY) Comparative Study on Malignant and Benign Human Cancer Cells and Tissues under Synchrotron Radiation, Acta Scientific Pharmaceutical Sciences 2.5: 30-35.

[346] Heidari, A. (2018). Small-Angle X-Ray Scattering (SAXS), Ultra-Small Angle X-Ray Scattering (USAXS), Fluctuation XRay Scattering (FXS), Wide-Angle X-Ray Scattering (WAXS), Grazing-Incidence Small-Angle X-Ray Scattering (GISAXS), Grazing-Incidence Wide-Angle X-Ray Scattering (GIWAXS), Small-Angle Neutron Scattering (SANS), Grazing-Incidence Small-Angle Neutron Scattering (GISANS), X-Ray Diffraction (XRD), Powder X-Ray Diffraction (PXRD), Wide-Angle X-Ray Diffraction (WAXD), Grazing-Incidence X-Ray Diffraction (GIXD) and Energy-Dispersive X-Ray Diffraction (EDXRD) Comparative Study on Malignant and Benign Human Cancer Cells and Tissues under Synchrotron Radiation, Oncol Res Rev, Volume 1 (1): $1-10$.

[347] Heidari, A. (2018). Pump-Probe Spectroscopy and Transient Grating Spectroscopy Comparative Study on Malignant and Benign Human Cancer Cells and Tissues with the Passage of Time under Synchrotron Radiation, Adv Material Sci Engg, Volume 2, Issue 1, Pages 1-7.

[348] Heidari, A. (2018). Grazing-Incidence Small-Angle X-Ray Scattering (GISAXS) and Grazing-Incidence Wide-Angle X-Ray Scattering (GIWAXS) Comparative Study on Malignant and Benign Human Cancer Cells and Tissues under Synchrotron Radiation, Insights Pharmacol Pharm Sci 1 (1): 1-8.

[349] Heidari, A. (2018). Acoustic Spectroscopy, Acoustic Resonance Spectroscopy and Auger Spectroscopy Comparative Study on Anti-Cancer Nano Drugs Delivery in Malignant and Benign Human Cancer Cells and Tissues with the Passage of Time under Synchrotron Radiation, Nanosci Technol 5 (1): 1-9.

[350] Heidari, A. (2018). Niobium, Technetium, Ruthenium, Rhodium, Hafnium, Rhenium, Osmium and Iridium Ions Incorporation into the Nano Polymeric Matrix (NPM) by Immersion of the Nano Polymeric Modified Electrode (NPME) as Molecular Enzymes and Drug Targets for Human Cancer Cells, Tissues and Tumors Treatment under Synchrotron and Synchrocyclotron Radiations, Nanomed Nanotechnol, 3 (2): 000138

[351] Heidari, A. (2018). Homonuclear Correlation Experiments such as Homonuclear Single- Quantum Correlation Spectroscopy (HSQC), Homonuclear Multiple-Quantum Correlation Spectroscopy (HMQC) and Homonuclear Multiple-Bond Correlation Spectroscopy (HMBC) Comparative Study on Malignant and Benign Human Cancer Cells and Tissues under Synchrotron Radiation, Austin J Proteomics Bioinform \& Genomics. [5] (1): 1024.

[352] Heidari, A. (2018). Atomic Force Microscopy Based Infrared (AFM-IR) Spectroscopy and Nuclear Resonance Vibrational Spectroscopy Comparative Study on Malignant and Benign Human Cancer Cells and Tissues under Synchrotron Radiation with the Passage of Time, J Appl Biotechnol Bioeng. [5] (3): 142-148.

[353] Heidari, A. (2018). Time-Dependent Vibrational Spectral Analysis of Malignant and Benign Human Cancer Cells and Tissues under Synchrotron Radiation, J Cancer Oncol, 2 (2): 000124.
[354] Heidari, A. (2018). Palauamine and Olympiadane Nano Molecules Incorporation into the Nano Polymeric Matrix (NPM) by Immersion of the Nano Polymeric Modified Electrode (NPME) as Molecular Enzymes and Drug Targets for Human Cancer Cells, Tissues and Tumors Treatment under Synchrotron and Synchrocyclotron Radiations, Arc Org Inorg Chem Sci 3 (1).

[355] Gobato, R., Heidari, A. (2018). Infrared Spectrum and Sites of Action of Sanguinarine by Molecular Mechanics and ab initio Methods, International Journal of Atmospheric and Oceanic Sciences. Vol. 2, No. 1, pp. 1-9.

[356] Heidari, A. (2018). Angelic Acid, Diabolic Acids, Draculin and Miraculin Nano Molecules Incorporation into the Nano Polymeric Matrix (NPM) by Immersion of the Nano Polymeric Modified Electrode (NPME) as Molecular Enzymes and Drug Targets for Human Cancer Cells, Tissues and Tumors Treatment Under Synchrotron and Synchrocyclotron Radiations, Med \& Analy Chem Int J, 2 (1): 000111.

[357] Heidari, A. (2018). Gamma Linolenic Methyl Ester, 5Heptadeca-5,8,11-Trienyl 1,3,4- Oxadiazole-2-Thiol, Sulphoquinovosyl Diacyl Glycerol, Ruscogenin, Nocturnoside B, Protodioscine B, Parquisoside-B, Leiocarposide, Narangenin, 7-Methoxy Hespertin, Lupeol, Rosemariquinone, Rosmanol and Rosemadiol Nano Molecules Incorporation into the Nano Polymeric Matrix (NPM) by Immersion of the Nano Polymeric Modified Electrode (NPME) as Molecular Enzymes and Drug Targets for Human Cancer Cells, Tissues and Tumors Treatment under Synchrotron and Synchrocyclotron Radiations, Int J Pharma Anal Acta, 2 (1): $007-$ 014.

[358] Heidari, A. (2018). Fourier Transform Infrared (FTIR) Spectroscopy, Attenuated Total Reflectance Fourier Transform Infrared (ATR-FTIR) Spectroscopy, Micro-Attenuated Total Reflectance Fourier Transform Infrared (Micro-ATR-FTIR) Spectroscopy, Macro- Attenuated Total Reflectance Fourier Transform Infrared (Macro-ATR-FTIR) Spectroscopy, Two-Dimensional Infrared Correlation Spectroscopy, Linear Two- Dimensional Infrared Spectroscopy, Non-Linear Two-Dimensional Infrared Spectroscopy, Atomic Force Microscopy Based Infrared (AFM-IR) Spectroscopy, Infrared Photodissociation Spectroscopy, Infrared Correlation Table Spectroscopy, Near-Infrared Spectroscopy (NIRS), Mid-Infrared Spectroscopy (MIRS), Nuclear Resonance Vibrational Spectroscopy, Thermal Infrared Spectroscopy and Photothermal Infrared Spectroscopy Comparative Study on Malignant and Benign Human Cancer Cells and Tissues under Synchrotron Radiation with the Passage of Time, Glob Imaging Insights, Volume 3 (2): 1-14. https://doi.org/10.15761/GII.1000153.

[359] Heidari, A. (2018). Heteronuclear Single-Quantum Correlation Spectroscopy (HSQC) and Heteronuclear Multiple-Bond Correlation Spectroscopy (HMBC) Comparative Study on Malignant and Benign Human Cancer Cells, Tissues and Tumors under Synchrotron and Synchrocyclotron Radiations, Chronicle of Medicine and Surgery 2.3: 144-156.

[360] Heidari, A. (2018). Tetrakis [3, 5-bis (Trifluoromethyl) Phenyl] Borate (BARF) - Enhanced Precatalyst Preparation Stabilization and Initiation (EPPSI) Nano Molecules, Medical Research and Clinical Case Reports 2.1: 113-126.

[361] Heidari, A. (2018). Sydnone, Münchnone, Montréalone, Mogone, Montelukast, Quebecol and Palau'amine-Enhanced Precatalyst Preparation Stabilization and Initiation (EPPSI) Nano Molecules, Sur Cas Stud Op Acc J. 1 (3).

[362] Heidari, A. (2018). Fornacite, Orotic Acid, Rhamnetin, Sodium Ethyl Xanthate (SEX) and Spermine (Spermidine or Polyamine) Nanomolecules Incorporation into the Nanopolymeric Matrix (NPM), International Journal of Biochemistry and Biomolecules, Vol. 4: Issue 1, Pages 1-19.

[363] Heidari, A., Gobato, R. (2018). Putrescine, Cadaverine, Spermine and Spermidine- Enhanced Precatalyst Preparation Stabilization and Initiation (EPPSI) Nano Molecules, Parana Journal of Science and Education (PJSE)-v.4, n.5, (1-14).

[364] Heidari, A. (2018). Cadaverine (1,5-Pentanediamine or Pentamethylenediamine), Diethyl Azodicarboxylate (DEAD or DEADCAT) and Putrescine (Tetramethylenediamine) Nano Molecules Incorporation into the Nano Polymeric Matrix (NPM) by Immersion of the Nano Polymeric Modified Electrode (NPME) as Molecular Enzymes and Drug Targets for Human Cancer Cells, Tissues and Tumors Treatment under Synchrotron and Synchrocyclotron Radiations, Hiv and Sexual Health Open Access Open Journal. 1 (1): 4-11.

[365] Heidari, A. (2018). Improving the Performance of NanoEndofullerenes in Polyaniline Nanostructure-Based Biosensors by Covering Californium Colloidal Nanoparticles with Multi-Walled 
Carbon Nanotubes, Journal of Advances in Nanomaterials, Vol. 3, No. 1, Pages 1-28. https://doi.org/10.22606/jan.2018.31001.

[366] Gobato, R., Heidari, A. (2018). Molecular Mechanics and Quantum Chemical Study on Sites of Action of Sanguinarine Using Vibrational Spectroscopy Based on Molecular Mechanics and Quantum Chemical Calculations, Malaysian Journal of Chemistry, Vol. 20 (1), 1-23.

[367] Heidari, A. (2018). Vibrational Biospectroscopic Studies on Anti-cancer Nanopharmaceuticals (Part I), Malaysian Journal of Chemistry, Vol. 20 (1), 33-73.

[368] Heidari, A. (2018). Vibrational Biospectroscopic Studies on Anti-cancer Nanopharmaceuticals (Part II), Malaysian Journal of Chemistry, Vol. 20 (1), 74-117.

[369] Heidari, A. (2018). Uranocene (U $\left.\left(\mathrm{C}_{8} \mathrm{H}_{8}\right)_{2}\right)$ and Bis(Cyclooctatetraene)Iron $\left(\mathrm{Fe}\left(\mathrm{C}_{8} \mathrm{H}_{8}\right)_{2}\right.$ or $\left.\mathrm{Fe}(\mathrm{COT})_{2}\right)$-Enhanced Precatalyst Preparation Stabilization and Initiation (EPPSI) Nano Molecules, Chemistry Reports, Vol. 1, Iss. [2], Pages 1-16.

[370] Heidari, A. (2018). Biomedical Systematic and Emerging Technological Study on Human Malignant and Benign Cancer Cells and Tissues Biospectroscopic Analysis under Synchrotron Radiation, Glob Imaging Insights, and Volume 3 (3): 1-7.

[371] Heidari, A. (2018). Deep-Level Transient Spectroscopy and XRay Photoelectron Spectroscopy (XPS) Comparative Study on Malignant and Benign Human Cancer Cells and Tissues with the Passage of Time under Synchrotron Radiation. Res Dev Material Sci. 7 (2). RDMS.000659.

[372] Heidari, A. (2018). A Clinical and Molecular Pathology Investigation of Correlation Spectroscopy (COSY), Exclusive Correlation Spectroscopy (ECOSY), Total Correlation Spectroscopy (TOCSY), Heteronuclear Single-Quantum Correlation Spectroscopy (HSQC) and Heteronuclear Multiple-Bond Correlation Spectroscopy (HMBC) Comparative Study on Malignant and Benign Human Cancer Cells, Tissues and Tumors under Synchrotron and Synchrocyclotron Radiations Using Cyclotron versus Synchrotron, Synchrocyclotron and the Large Hadron Collider (LHC) for Delivery of Proton and Helium Ion (Charged Particle) Beams for Oncology Radiotherapy. Euro. J. Adv. Engg. Tech., 5(5):414-426.

[373] Heidari, A. (2018). C70-Carboxyfullerenes Nano Molecules Incorporation into the Nano Polymeric Matrix (NPM) by Immersion of the Nano Polymeric Modified Electrode (NPME) as Molecular Enzymes and Drug Targets for Human Cancer Cells, Tissues and Tumors Treatment under Synchrotron and Synchrocyclotron Radiation. Glob Imaging Insights, Volume 3 (3): 1-7.

[374] Heidari, A. (2018). Adamantane, Irene, Naftazone and Pyridine-Enhanced Precatalyst Preparation Stabilization and Initiation (PEPPSI) Nano Molecules. Madridge J Nov Drug Res. 2 (1): 61-67. 